\title{
Microneedle-based drug delivery: materials of construction
}

\author{
SHUBHMITA BHATNAGAR (D), PRADEEPTHA REDDY GADEELA, \\ PRANATHI THATHIREDDY and VENKATA VAMSI KRISHNA VENUGANTI* ${ }^{*}$ \\ Department of Pharmacy, Birla Institute of Technology and Science (BITS) Pilani, Hyderabad Campus, \\ Hyderabad, Telangana 500078, India \\ E-mail: vamsi@hyderabad.bits-pilani.ac.in \\ Pradeeptha Reddy Gadeela and Pranathi Thathireddy have contributed equally to this work.
}

MS received 29 March 2019; revised 6 May 2019; accepted 15 May 2019

\begin{abstract}
Microneedle-based drug delivery has attracted researchers' attention over the last decade. The material of construction of microneedles has emerged as a critical factor influencing clinical usage, manufacture, drug loading and drug stability. Initially, microneedles were fabricated using glass, silicon and metals. The development of sophisticated machining tools and advances in the polymer science allowed for a major shift in materials of construction of microneedles towards polymeric systems. Delivery of difficult to formulate therapeutics, including proteins, peptides, vaccines and genetic material has been established using microneedles. There is a constant search for newer materials, which can easily form microneedles with sufficient strength to penetrate biological barriers, can be easily manufactured, and are compatible with drug molecules and biological systems. While several reviews have discussed microneedle-based cosmetic and drug delivery applications, there is a gap in understanding the effect of material of construction of microneedles on drug stability and potential for large-scale manufacture. This review is an attempt to present microneedles as a function of the material used for its construction. Since microneedle commercialization is now a realistic possibility, we believe that improved understanding of materials and their chemistry will allow for improved decision making, especially for industries looking towards bringing microneedle technology to manufacturing setups.
\end{abstract}

Keywords. Microneedles; materials; microfabrication; transdermal drug delivery; tensile strength.

\section{Introduction}

Biological barriers are important for survival. Skin membrane protects the body from different environmental insults and maintains homeostasis. The mucosal lining in the gut protects the underlying layers from acid erosion. However, this protective nature would limit drug delivery through these barriers. For example, skin does not allow most molecules to permeate to deeper dermal layers. ${ }^{1}$ The needle and the syringe have been developed to overcome these barriers and deliver therapeutics directly to the affected areas or to the blood. However, shortcomings with syringe-based injections decrease their patient compliance. Syringe injections are painful, require trained medical personnel for administration, can cause infections and needle stick injuries and generate high volumes of non-

*For correspondence biodegradable waste. ${ }^{2}$ Strategies have been developed to overcome biological barriers, especially the skin, using non-invasive and minimally invasive techniques. Microneedles (MNs) are an attractive strategy for minimally invasive delivery of molecules across barriers. When used for transdermal delivery, they penetrate the skin to upper layers of the dermis, causing no pain or bleeding. ${ }^{3}$ These micron-sized sharp needles can directly deliver molecules across the skin, the cornea or back of the eye, or even the gut membrane. ${ }^{4,5}$

MNs have been employed for drug delivery, vaccination, bio-sensing and diagnostic purposes. They can be broadly classified based on their shape (conical, pyramidal, obelisk, etc.), material of construction (metal, glass, silicon, polymer, etc.), or technique of drug loading and delivery (hollow, solid, coated, etc.). ${ }^{2}$ Broadly, drug delivery using different types of MNs have been classified into five different approaches (Figure 1). 


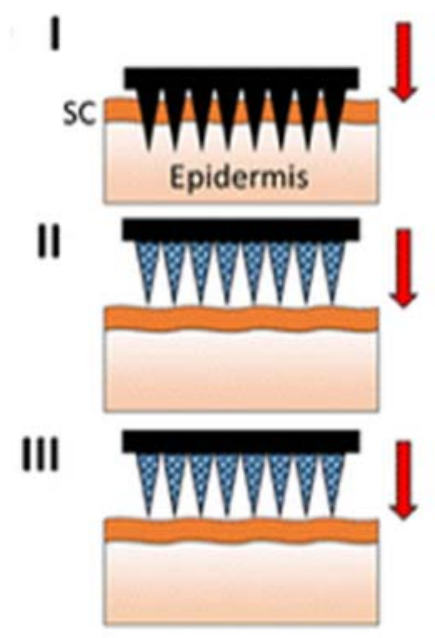

IV
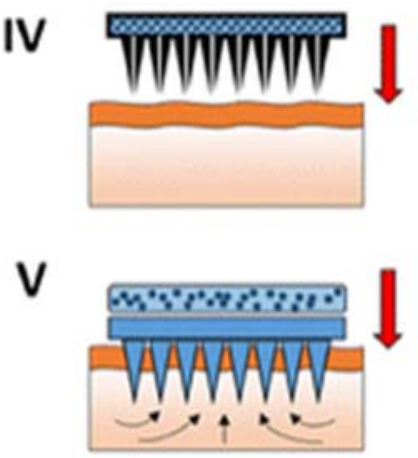
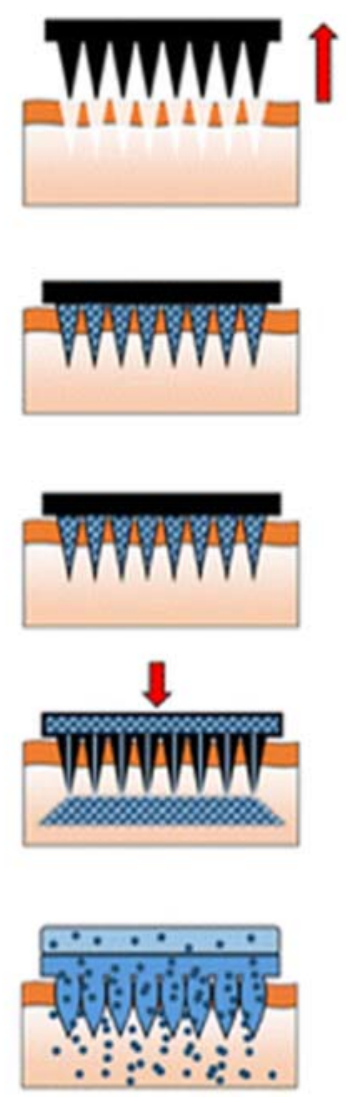

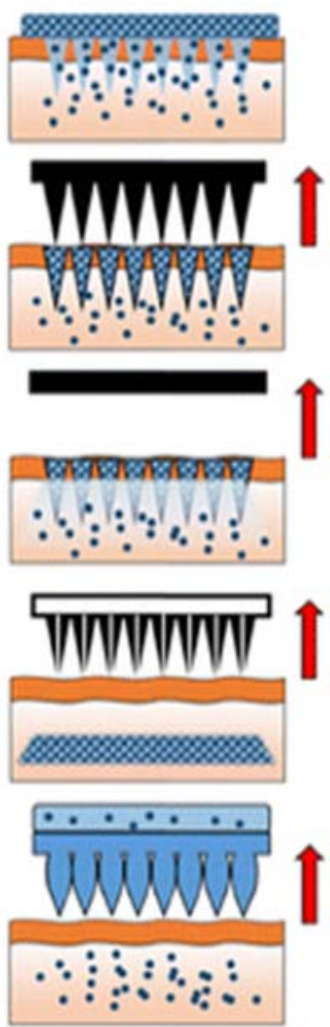

Figure 1. Transdermal drug delivery approaches using MNs. I - 'poke and patch' approach; II - 'coat and poke' approach; III - 'poke and release' approach; IV - 'poke and flow' approach; V - 'poke and swell' approach. Image adapted with permission from. ${ }^{6}$

In the 'poke and patch' approach, MNs-generally metal solid MNs - are used to create micropores in the skin, which allow easier penetration of drug molecules subsequently applied on the treated surface as a solution, ointment or transdermal patch. The 'coat and poke' approach utilizes MNs that have been previously coated with the molecule to be delivered. The coated MNs are allowed to penetrate the skin and left in the skin intermittently for the coating to dissolve before intact removal. MNs which are formed from materials that can disintegrate and subsequently dissolve in the interstitial fluid, constitute the 'poke and release' approach. These MNs are prepared using dissolving polymers or sugars and dissolve within seconds to a few minutes. ${ }^{7}$ MNs with hollow cores have been used for delivery of larger volumes of liquids in the body (Figure $1 \mathrm{IV}$ ). These MNs allow for liquid formulations to be injected into the body in a painless fashion. The two FDA approved MN-based devices (BD Soluvia ${ }^{\circledR}$ and the Nanopatch ${ }^{\circledR}$ ) currently in the market use this approach to deliver influenza vaccine intradermally. Hollow MNs also find potential in diagnostic applications. ${ }^{8}$ The 'poke and swell' approach utilizes hydrogel-forming MNs, that take up interstitial fluid and swell. ${ }^{9}$

Of different parameters, the material of construction of MNs has emerged as a critical factor in the manufacture and usage of MNs. Different shapes and designs of MNs require specific properties of material for preparation. In the early stages of MN development, MNs were exclusively prepared using silicon. ${ }^{2}$ These were solid MNs prepared using lithography. Soon after, hollow glass MNs were prepared using glass-blowing and pulling. These MNs were tested for intradermal delivery of influenza. Over the years, newer materials for MN preparation, especially polymers have been developed. An exponential increase in MN based publications for newer materials such as polymers has been seen over the last five years. Figure 2 provides a relative estimate for the number of studies published with MNs prepared from different materials. More than half of the published literature on MNs is based on polymer-based MNs which also increased with time. The current review provides an understanding of materials used for $\mathrm{MN}$ fabrication and how material properties affects critical parameters 

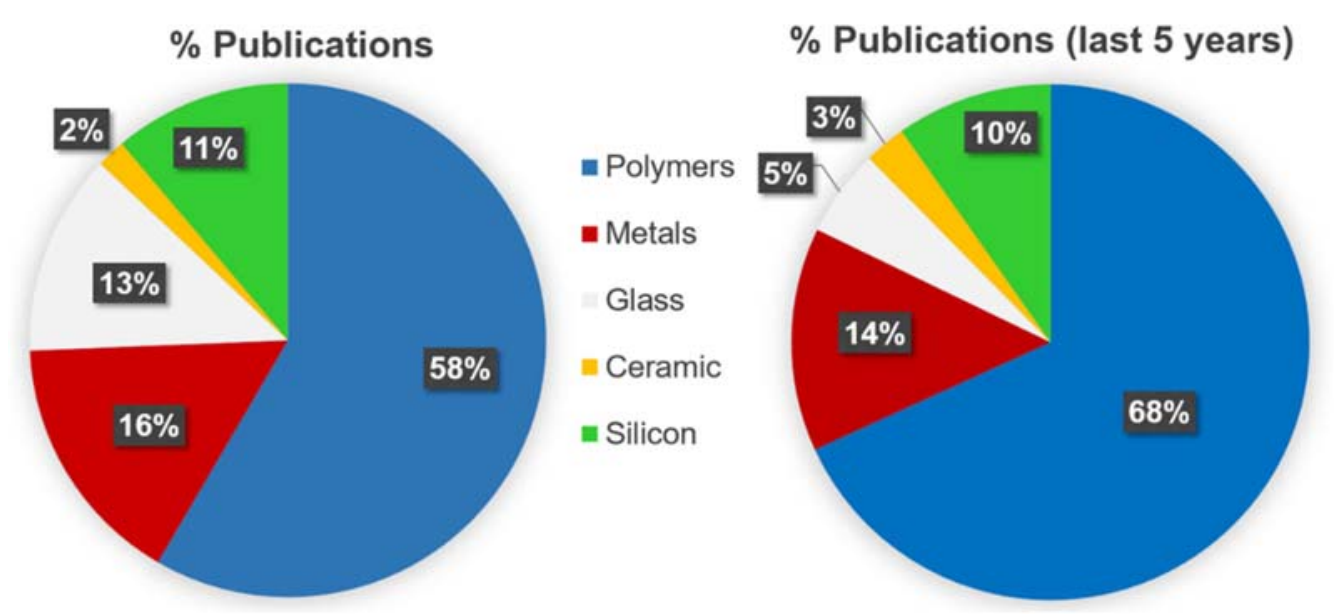

Figure 2. Percentage publications for MNs prepared using different materials. Percentages were calculated based on hits for different keywords. Search was performed https://www.ncbi.nlm.nih.gov/pubmed/ and sorted by Best Match. Keywords used were 'metal MN', 'glass MN', 'ceramic MN', 'silicon MN' and 'polymer MN'. Search date: 01 March 2019.

such as stability, tensile strength, and biocompatibility of MNs. Additionally, techniques for MN fabrication are discussed. While MN have been used for cosmetic purposes and to deliver drugs to other parts of the body, this review is limited to MNs used for drug delivery across skin, unless specified otherwise.

\section{Materials for MN construction}

\subsection{Established materials for MN construction}

2.1a Silicon and silica glass: Silicon is a hard and brittle crystalline solid and the eighth-most common element in the universe and the second on Earth. Silicon compounds such as silicon glass find use in medical industry. ${ }^{10}$ The first MNs for drug delivery were made of silicon. Silicon MNs provide good tip sharpness but are susceptible to breaking due to their fragile nature. Also, silicon MN manufacture is expensive and requires a clean room setup. ${ }^{11}$ Typical silicon MNs are shown in Figure $4 \mathrm{~b}$ and $4 \mathrm{c}$. Silica glass, an amorphous, transparent, and inert solid, is a material of choice for laboratory usage and few therapeutic applications. ${ }^{12}$ Grades of glasses are defined based on their transparency and inertness. For pharmaceutical use, Type I Highly Resistant Borosilicate Glass, which has the least chemical reactivity, lowest thermal expansion coefficient and highest Young's modulus, is used. ${ }^{13}$ Figure 3 shows the Ashby plot for tensile strength Vs. Young modulus for different materials. Silica glass, seen towards the centre of the plot possesses good tensile strength and a high Young's modulus.

In 1961, Chambers used glass MNs for micromanipulation of individual living cells. ${ }^{14}$ Since then, glass MNs have been used as force probes to study muscle physiology. ${ }^{15,16}$ Glass MNs are generally prepared by micropipette pulling. ${ }^{17}$ The use of hollow glass MNs was suggested for drug delivery and diagnostic purposes. Prausnitz and colleagues investigated glass MNs for collecting dermal interstitial fluid for glucose monitoring in $2005 .^{18}$ The group further reported the use of glass MNs for microinjection in 2006. ${ }^{19}$ Glass MNs have since then been studied for delivering insulin in animals and humans. These glass MNs penetrated the skin up to $1.5 \mathrm{~mm}$ and had a radius of $15-40 \mu \mathrm{m}$ at the needle tip with a cone angle of $20-30^{\circ}$ (Figure $4 \mathrm{a}$ ). Since glass can withstand very high temperatures, glass $\mathrm{MNs}$ could be easily sterilized using dry or moist heat sterilization. However, making glass needles is a time consuming and difficult to calibrate process since the glass is handpulled. ${ }^{20}$ The use of glass MNs is limited to experimentation and has not realized into commercial setups.

2.1b Metals: Metals and their alloys have been used in the biomedical field for generations. Metals generally possess good malleability and ductility and a high Young's modulus. (Table 1 and Figure 3) Metal alloys can be made more stable and useful for biomedical applications. Hypodermic needles are now typically made from stainless steel while titanium finds widespread usage in implants and prostheses. 316L type stainless steel (316L SS) is the most used alloy in all implant categories ranging from cardiovascular to otorhinology ${ }^{58}$ Titanium is lightweight with a density of $4.5 \mathrm{~g} / \mathrm{cm}^{3}$ compared to $7.9 \mathrm{~g} / \mathrm{cm}^{3}$ for 316 stainless steel and $8.3 \mathrm{~g} / \mathrm{cm}^{3}$ for cast CoCrMo alloys. ${ }^{59} \mathrm{Ti}$ and its alloys such as Ti6Al4V are known for their excellent tensile strength (Table 1) and pitting corrosion resistance and find usage in biomedical applications. ${ }^{60}$ When the implant requires high wear resistance such as artificial joints, CoCrMo alloys are used. ${ }^{61}$

Stainless steel was the first metal used in the production of MN arrays. Metal MNs have been obtained by manually pressing the tips of the smallest available stainless steel hypodermic needles through a supporting material of 


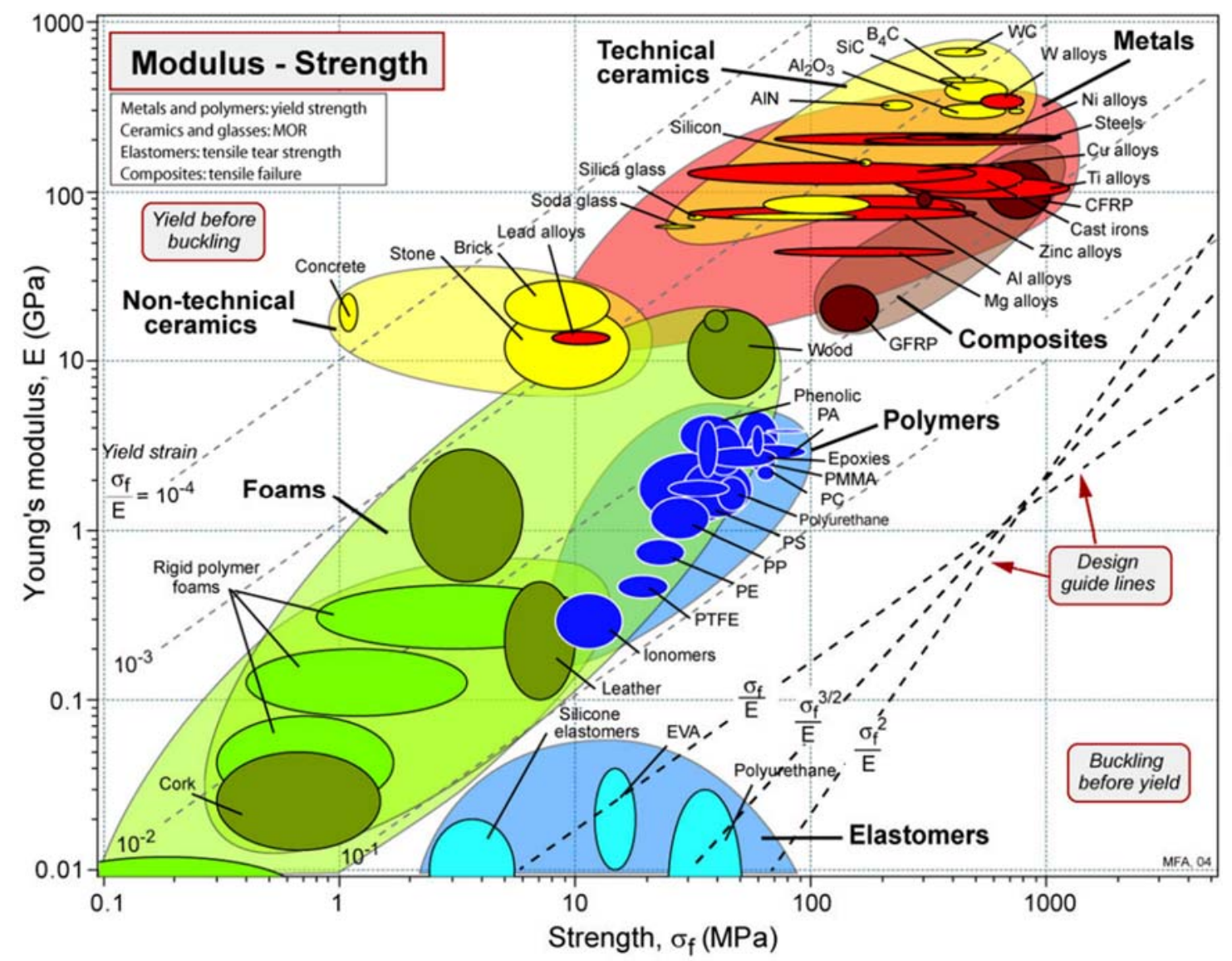

Figure 3. Ashby plot for Young's modulus Vs. Strength for different materials. Image reprinted from. ${ }^{21} \odot$ Granta Design.
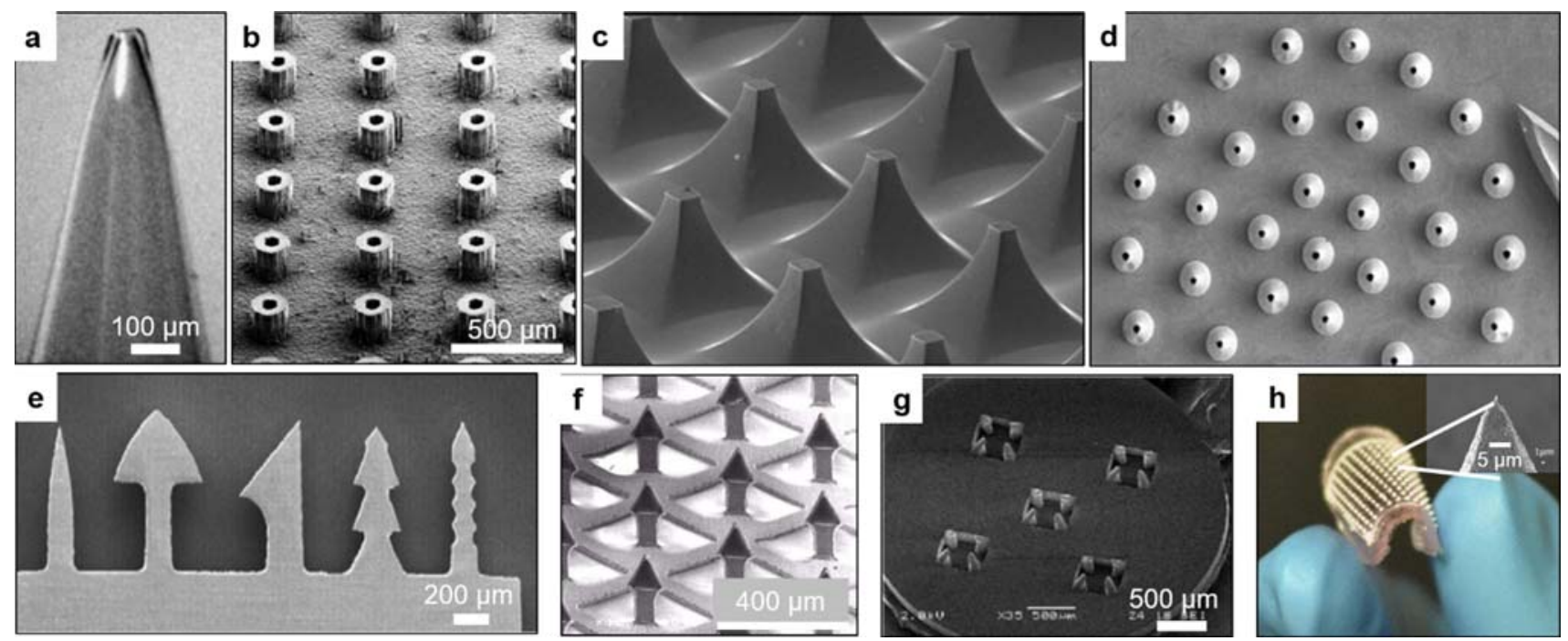

Figure 4. (a) Hollow Type I Glass $\mathrm{MN},{ }^{19}$ (b) hollow silicon MN array, ${ }^{64}$ (c) solid silicon micro-enhancer array, ${ }^{65}$ (d) an array of hollow metal MNs ${ }^{66}{ }^{\circ}(2003)$ National Academy of Sciences, (e) MNs with varied geometries such as barbs and serrated edges, ${ }^{67}$ (f) an array of parathyroid hormone coated titanium MNs, ${ }^{68}(\mathrm{~g})$ a ceramic nanoporous MN array ${ }^{69}(\mathrm{~h})$ an array of bioceramic MNs with a flexible gelatin base. ${ }^{70}$ Images reprinted with permission from indicated references.

defined thickness or by laser cutting metal sheets into MN shapes and bending them out of plane. ${ }^{6,62}$ Additionally, other microfabrication technologies including 3D laser ablation, wet etching and metal electroplating methods have been adopted to prepare metal MNs of different shapes and geometries. ${ }^{3}$ Solid metal MNs can be coated with molecules 
Table 1. Young's moduli and tensile strength values for different materials reported for MN fabrication.

\begin{tabular}{|c|c|c|c|}
\hline Material & Young's modulus & Tensile strength & Reference(s) \\
\hline Borosilicate glass type 1 & 61-64 GPa & $22-32 \mathrm{MPa}$ & 22,23 \\
\hline Silicon & 130 to $188 \mathrm{GPa}$ & $6900 \mathrm{MPa}$ & 24,25 \\
\hline Nickel & $207 \mathrm{GPa}$ & $419 \mathrm{MPa}$ & 26,27 \\
\hline Titanium & $115 \mathrm{GPa}$ & $470 \mathrm{MPa}$ & 28 \\
\hline Stainless steel 316 & $193 \mathrm{GPa}$ & $580 \mathrm{MPa}$ & 29 \\
\hline SU-8 & $2.8-3.2 \mathrm{GPa}$ & $34-40 \mathrm{MPa}$ & 30 \\
\hline Ormocer & $17 \mathrm{GPa}$ & $30 \mathrm{MPa}$ & 6 \\
\hline Collagen type 1(fibrils) & $0.2-0.86 \mathrm{GPa}$ & $0.5 \mathrm{GPa}$ & 31,32 \\
\hline $\begin{array}{l}\text { Sodium CMC films } \\
(2 \% \text { w/v with glycerol })\end{array}$ & $1.04 \pm 0.04 \mathrm{GPa}$ & $40.1 \pm 0.9 \mathrm{MPa}$ & 33 \\
\hline L-PLA $(50,000)$ & $1200 \mathrm{MPa}$ & $28 \mathrm{MPa}$ & 34 \\
\hline Poly(d,1-lactide-co-glycolide) 50/50 & $2.02 \mathrm{GPa}$ & & 35 \\
\hline Zein & $28-86 \mathrm{MPa}$ & $\begin{array}{l}22.9 \pm 1.62 \mathrm{MPa} \\
\text { (for thin films) }\end{array}$ & 36,37 \\
\hline PVA (thin film) & $490.411 \mathrm{MPa}$ & $0.3485 \mathrm{MPa}$ & 38 \\
\hline Alumina, $>99 \%$ & 380-410 GPa & $260 \mathrm{MPa}$ & 39 \\
\hline Hydroxyapatite (HAP) & $35-120 \mathrm{GPa}$ & $\begin{array}{c}35 \mathrm{MPa} \\
\text { (diametrical strength for } \\
100 \% \text { dense HAP) }\end{array}$ & 40,41 \\
\hline Hyaluronic acid (HA) & $\begin{array}{c}39.9 \pm 6.7 \mathrm{kPa} \text { (crosslinked with } \\
10 \% \text { PEG 2000) }\end{array}$ & & 42 \\
\hline $\begin{array}{l}\text { PDMS } \\
\text { (membrane } 200 \mu \mathrm{m} \text { thick) }\end{array}$ & $\sim 900 \mathrm{kPa}$ & $\sim 25 \mathrm{MPa}$ & 43 \\
\hline $\begin{array}{l}\text { Gelatin (Bovine hide gelatin type B, } \\
\text { Bloom 200, 20\% w/v) }\end{array}$ & $40-70 \mathrm{kPa}$ & $\sim 21 \mathrm{kPa}$ & 44 \\
\hline $\begin{array}{l}\text { Sodium alginate } \\
\text { (thin films) }\end{array}$ & NA & $33.6 \pm 3.1 \mathrm{MPa}$ & 45 \\
\hline CoNiCrMo & $232 \mathrm{GPa}$ & $793 \mathrm{MPa}$ & 46 \\
\hline Ti6Al4V (F136) & $116 \mathrm{GPa}$ & $860 \mathrm{PPa}$ & 46 \\
\hline Pure iron & $200 \mathrm{GPa}$ & $210 \mathrm{MPa}$ & 46 \\
\hline Sucrose (1:1 with CMC) & $22 \mathrm{MPa}$ & $22.1 \mathrm{MPa}$ & 47 \\
\hline Maltose (1:1 with CMC) & $7.42 \mathrm{GPa}$ & $7.44 \mathrm{GPa}$ & 47 \\
\hline Trehalose (1:1 with CMC) & $5.69 \mathrm{GPa}$ & $5.66 \mathrm{GPa}$ & 47 \\
\hline Mannitol & $\begin{array}{c}25 \pm 1 \mathrm{kPa} \\
\text { (spray-dried cake) }\end{array}$ & $\begin{array}{c}\sim 1 \mathrm{MPa} \\
(\text { at } 1 \mathrm{MPa} \text { compression } \\
\text { pressure) }\end{array}$ & 48,49 \\
\hline Sorbitol (1:1 with CMC) & $1.97 \pm 1.70 \mathrm{GPa}$ & NA & 50 \\
\hline Gantrez $^{\circledR}$ AN 139 (MNs) & $6.56 \pm 0.56 \mathrm{GPa}$ & NA & 51 \\
\hline Polyethylene & $0.7 \mathrm{GPa}$ & $20-30 \mathrm{MPa}$ & 52 \\
\hline Polyurethane (PU) thermoplastics & $1.31-2.07 \mathrm{GPa}$ & $31-62 \mathrm{MPa}$ & 53 \\
\hline Polycarbonate (PC) & $2-2.4 \mathrm{GPa}$ & $55-75 \mathrm{MPa}$ & 54 \\
\hline Aluminium oxide & $370 \mathrm{GPa}$ & $300 \mathrm{MPa}$ & 55 \\
\hline Polystyrene & $3.4 \mathrm{GPa}$ & $48 \mathrm{MPa}$ & 56 \\
\hline PMMA & $2450 \mathrm{MPa}$ & $62 \mathrm{MPa}$ & 57 \\
\hline
\end{tabular}

CMC: carboxymethyl cellulose; PLA: polylactic acid; PVA: polyvinyl alcohol, PMMA: Poly(methyl methacrylate).

of interest with or without a layer of polymer. Hollow MNs are also generally made out of metal (Figure 4d). They are often made from metal tubing by laser machining, electrochemical etching or by electrode discharge machining. ${ }^{3}$ Other metals that have been used for MN fabrication include titanium (Figure 4f), tantalum, and nickel. ${ }^{63}$

2.1c Ceramics: Ceramics are solid materials composed of inorganic compounds of a metal, non-metals or metalloids. Ceramics are solid, possess thermal and electrical insulator properties and a brittle nature. ${ }^{71}$ Biocompatible ceramics possess higher mechanical strength and high temperature and moisture stability than most polymers. The porosity of ceramics can be easily tailored during production. This property of ceramics in addition to electrostatic interaction between the ceramic surface and permeants can be exploited to enhance transdermal permeation of molecules. ${ }^{72}$ Most common ceramics used as biocompatible materials are those between aluminium and oxygen (alumina, $\mathrm{Al}_{2} \mathrm{O}_{3}$ ), 

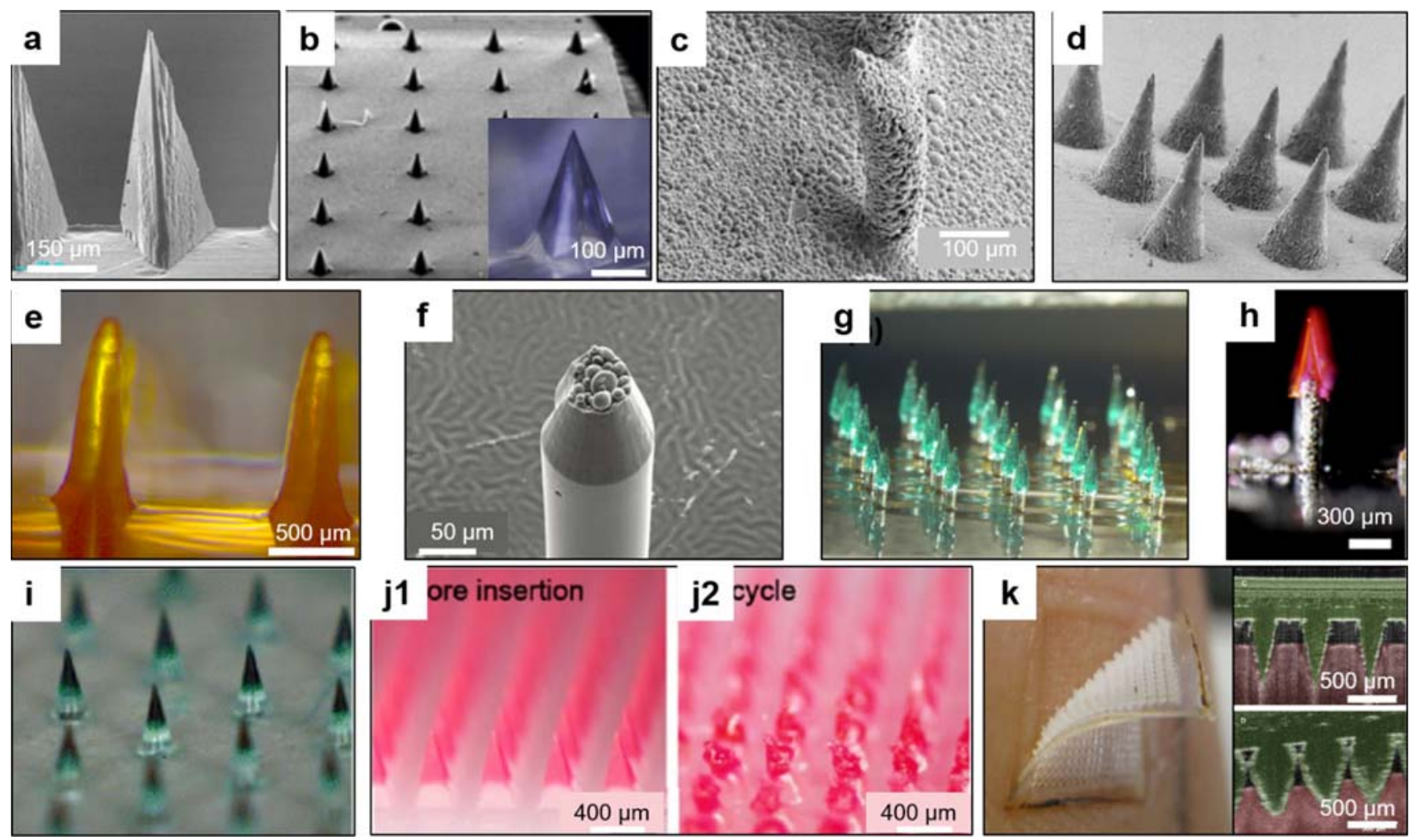

Figure 5. (a) MNs fabricated from Maltose, ${ }^{2}$ (b) An array of sugar-glass MNs, ${ }^{84}$ (c) porous MN fabricated using PLAmicroparticles cured by ultrasonic welding, ${ }^{117}$ (d) Gantrez ${ }^{\circledR}$ AN 139 based MN array, ${ }^{118}$ (e) Zein MNs, ${ }^{85}$ (f) PLGA MN showing internal PLA microparticles, ${ }^{119}$ (g) MN array fabricated from SU-8, ${ }^{120}$ (h) Separable arrowhead MNs made of PVA/PVP, ${ }^{121}$ (i) chondroitin sulphate MNs, ${ }^{122}$ CSpringer Nature (2011), (j) NIR-responsive silica-coated lanthanum hexaboride particles filled in PCL MNs (1) after insertion and (2) after one cycle of NIR irradiation ${ }^{123}$ CAmerican Chemical Society (2015), (k) Hydrogel forming swellable PMVE/MA-PEG MNs showing swelling behaviour after insertion in forearm skin of a human volunteer. ${ }^{124}$ Images reprinted with permission from indicated references.

calcium and oxygen $(\mathrm{CaO})$, and silicon and nitrogen (silicon nitride, $\left.\mathrm{Si}_{3} \mathrm{~N}_{4}\right)$. Alumina and Zirconia $\left(\mathrm{ZrO}_{2}\right)$ are commonly used to fabricate ceramic $\mathrm{MNs}{ }^{73}$ Alumina is biologically inert, stable at high temperatures but brittle under tensile stress. ${ }^{74}$ Since alumina is sintered at higher temperatures, the loading of thermo-labile molecules could be a challenge. Zirconia offers higher toughness and strength than alumina but has poor wear characteristics (Figure 3). Calcium compounds, calcium sulphate and hydroxyapatite are also attractive materials for fabrication of MNs. ${ }^{75,76}$ Figure $4 \mathrm{~g}$ shows a ceramic nanoporous MN array while Figure $4 \mathrm{~h}$ shows bioceramic arrays attached to a flexible $\mathrm{MN}$ base made of gelatin.

Ceramic MN are typically prepared using micromolding of a ceramic slurry followed by sintering at high temperatures. The slurry parameters can be adjusted to result in variations in ceramic morphology, porosity and strength. Organically modified ceramic, Ormocer ${ }^{\circledR}$ has been used to prepare MNs. Ormocer ${ }^{\circledR}$ is synthesized through a solution and gelation process (sol-gel process) from multi-functional urethane and thioether(meth)acrylate alkoxysilanes. ${ }^{77}$ Ceramic MNs prepared using $\mathrm{CaS}$ and $\mathrm{CaP}$ were used to study the release of loaded zolpidem tartarate in the skin. ${ }^{78}$ In another study, nanoporous ceramic MNs made from alumina were employed for transcutaneous vaccination. $^{69}$

2.1d Carbohydrates: Melts, solutions or slurries of carbohydrates can easily form MNs by micromolding in metal or PDMS molds. These MNs generally dissolve quickly by taking up interstitial fluid and releasing the entrapped drug molecule. Carbohydrates offer a cheap and safe alternative for metals and glass. However, carbohydrate needles possess lower tensile strength and need to be combined with other materials for increasing the strength. Maltose is the most commonly used sugar for preparation of MNs. It is a GRAS material commonly used as a bulking agent in many pharmaceutical dosage forms. ${ }^{79}$ Maltose needles were studied for the transdermal permeation of nicardipine hydrochloride across rat skin. Maltose MNs, $508.46 \pm 9.32 \mu \mathrm{m}$ long with a tip radius of $3 \mu \mathrm{m}$ were prepared by micromolding (Figure 5a). Pre-treatment of skin with maltose MN significantly improved flux of nicardipine across the skin in comparison with untreated skin. ${ }^{79}$ Maltose MNs were further studied for transdermal delivery of human $\operatorname{IgG}^{80}$ Other sugars (trehalose, sucrose, mannitol, fructose, raffinose and sorbitol) in combination with polymers have been studied for preparation of MNs. ${ }^{50,81-84}$ An experimental study conducted in 
addition with finite element analysis (FEM) to study the mechanical properties of MNs suggested that MNs made of $\mathrm{CMC} /$ maltose are better to those made of $\mathrm{CMC} /$ trehalose and $\mathrm{CMC} /$ sucrose in terms of mechanical strength. This was correlated with Young's modulus of sugar and the depth of skin penetration. ${ }^{47}$ Table 1 lists the Young's moduli and tensile strength values of sugars used for MN manufacture. Polysaccharides also present themselves as a good choice for MN fabrication. They are reviewed in the next section on polymers.

2.1e Polymers: Polymers have revolutionized the field of drug delivery. The first instance of polymer science is the derivatization of naturally occurring cellulose to celluloid and cellulose acetate by Henri Braconnot in the 1830s. ${ }^{110}$ In 1922, Hermann Staudinger first proposed that polymers were long chains of atoms held together by covalent bonds. ${ }^{111}$

Polymers attract wide attention for $\mathrm{MN}$ fabrication due to their biocompatibility, biodegradability and low cost. In general, polymers possess lower tensile strength than metals or silicon, however, they are tougher than most other materials used for MN fabrication (Table 1 and Figure 3). A number of naturally occurring polymers have been used for casting of MNs. These include naturally occurring proteins, polysaccharides, semisynthetic and synthetic polymers. In general, polymers are used to prepare solid dissolvable or swellable MNs or used as a coating on solid structures made of other materials, however, studies have also reported polymer MNs which are hollow, and nondissolving. ${ }^{112}$ A list of various polymers used for fabrication of MNs is provided in Table 2. Polymer MNs are majorly fabricated using a lithographic or molding process. Biodegradable or dissolving polymeric MN releases the drug molecules from the matrix for localized or systemic delivery. Dissolving systems are usually prepared with polysaccharides, the major ones being CMC, amylopectin, dextrin, hydroxypropyl cellulose, alginate, chondroitin, and hyaluronic acid. These materials present sufficient hardness for penetration into biological barriers like the skin or cornea (Table 1). They provide rapid action as these materials quickly dissolve upon contact with aqueous fluid. Tip dissolving chondroitin sulphate needles are shown in Figure 5i. Synthetic polymers for $\mathrm{MN}$ fabrication include PMVE/MAH (commercially available as Gantrez ${ }^{\circledR}$ by Ashland corporation), PVP and PVA. MNs prepared using Gantrez $^{\circledR}$ (Figure 5d) are reported to be strong and resist compression forces up to $0.7 \mathrm{~N} /$ needle without yielding. ${ }^{113}$ This plastic polymer has been widely studied for delivery of various small molecules, proteins and vaccines. Further, PVA and PVP present a good alternative material for the preparation of dissolvable MNs. Available in various grades and molecular weights, the strength of PVA or PVP needles can be easily tuned. PVA is a water-soluble plastic polymer and approved for usage in a number of pharmaceutical formulations. Composites of PVA and PVP provide good plasticity and dissolvability to MNs. ${ }^{114}$ These polymers are a choice for preparation of MNs for ocular use due to their quick disintegration and compatibility with tear fluid. ${ }^{115}$ Collagen and its derivatives, silk, gelatin and zein are few protein-based materials that have been used for MN fabrication. Protein MNs are hypothesized to interact better with protein-based drugs and vaccines and assist in high drug loading and better stability of MNs. ${ }^{85}$ These materials also offer a low-cost option for preparing MNs as they are largely inexpensive and easy to fabricate using micromolding. ${ }^{116}$

Accumulation of polymers in the skin is a concern with the use of dissolving needles. As an alternative, hydrogelforming swellable polymeric MNs which swell upon contact with interstitial fluid releasing encapsulated drug by a diffusion or wicking mechanism has been developed. These needles do not dissolve and can be removed intact from the skin as shown in Figure $5 \mathrm{k}$. As the needles swell by taking up interstitial fluid, they can pick up molecules, such as biomarkers which could be analyzed after extraction from the matrix. The tips further swell and provide a conduit or transport of medication from the base, backing layer or a reservoir (Figure 1). Hydrogel forming needles have been successfully prepared using polysaccharide mixtures, gelatin, PVA and CMC. ${ }^{9}$ Figure $5 \mathrm{k}$ shows hydrogel-forming needles being removed from the skin after $1 \mathrm{~h}$ of application and the swelling behaviour of needles after $2 \mathrm{~h}$ of application onto the human forearm.

2.1f Advanced materials and combinations: MNs have evolved from solid or hollow structures to newer concepts employing the use of biofunctional materials. Surface modifications for better drug loading and release, combination of complex nanosystems with MNs and integrated sensing and control systems for responsive on-demand drug delivery are few examples. Advancements have been made in glucose measurement with algorithmic spatial control glucose measuring and a feedback mechanism to deliver insulin on-demand. ${ }^{125} \mathrm{MNs}$ have shown potential to be developed as minimally invasive continuous glucose monitoring systems. MNs for glucose monitoring employs an electrochemical sensing probe within a hollow MN. The hollow MNs pick up interstitial fluid in its lumen. Hydrogen peroxide $\left(\mathrm{H}_{2} \mathrm{O}_{2}\right)$ - produced from glucose by glucose oxidase - is measured at the working electrode. Further, glucose-responsive mechanisms can be employed to deliver drugs. Generally, hypoxia sensitive systems, also incorporated in the same $\mathrm{MN}$ array or a connected array, release encapsulated drug as hypoxia is developed after consumption of oxygen in the reaction. Alternatively, generated $\mathrm{H}_{2} \mathrm{O}_{2}$ can be used to activate drug release from $\mathrm{H}_{2} \mathrm{O}_{2}$ responsive systems. $\mathrm{Hu}$ et al., report an $\mathrm{MN}$ integrated $\mathrm{H}_{2} \mathrm{O}_{2}$-responsive polymeric vesicular system for insulin delivery. ${ }^{126}$ These self-assembled vesicles were prepared using block copolymer incorporated with polyethylene glycol (PEG) and phenylboronic ester-conjugated polyserine and laden with glucose oxidase and insulin. Sensitization of these responsive systems can be increased further by 


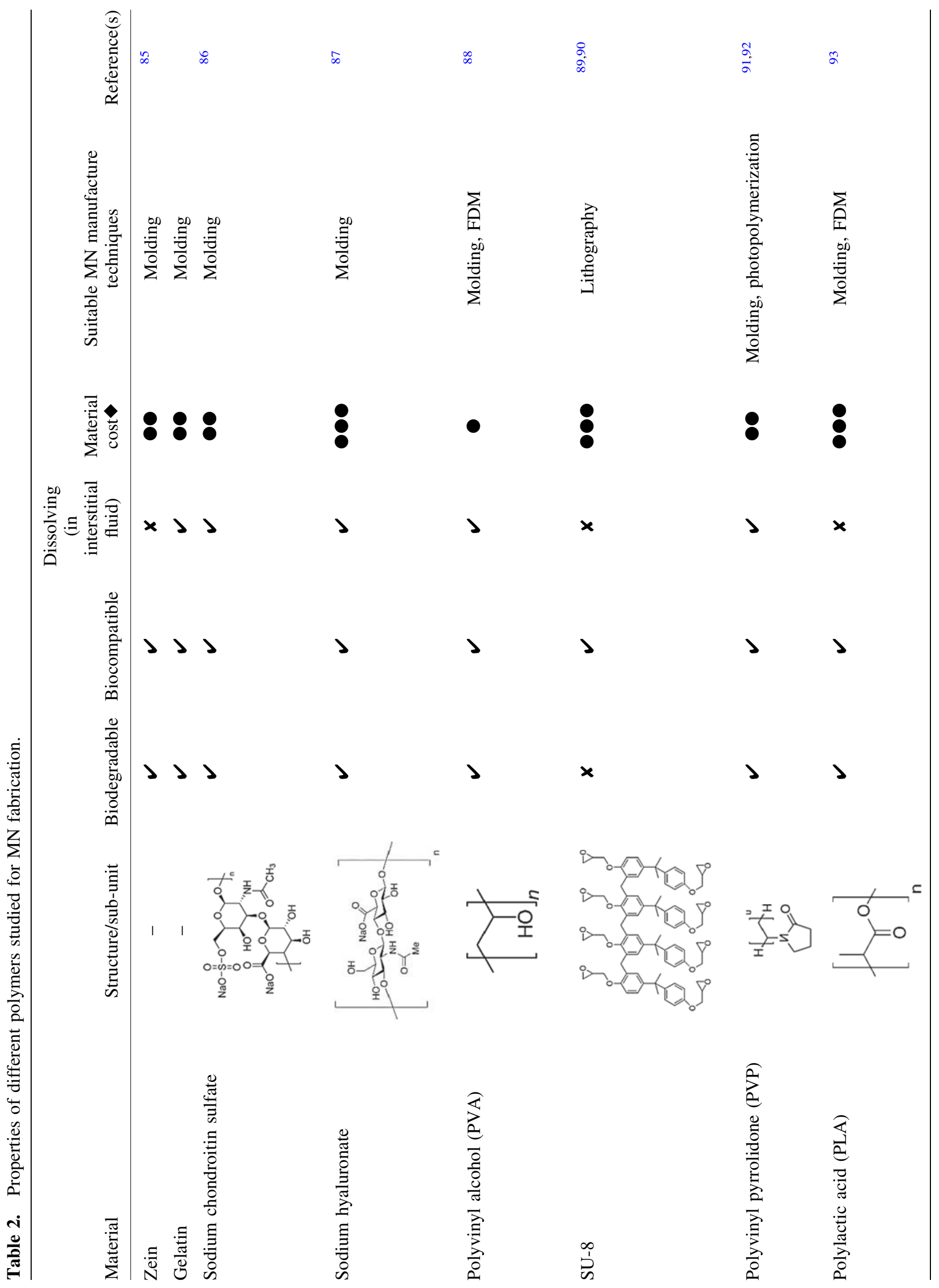




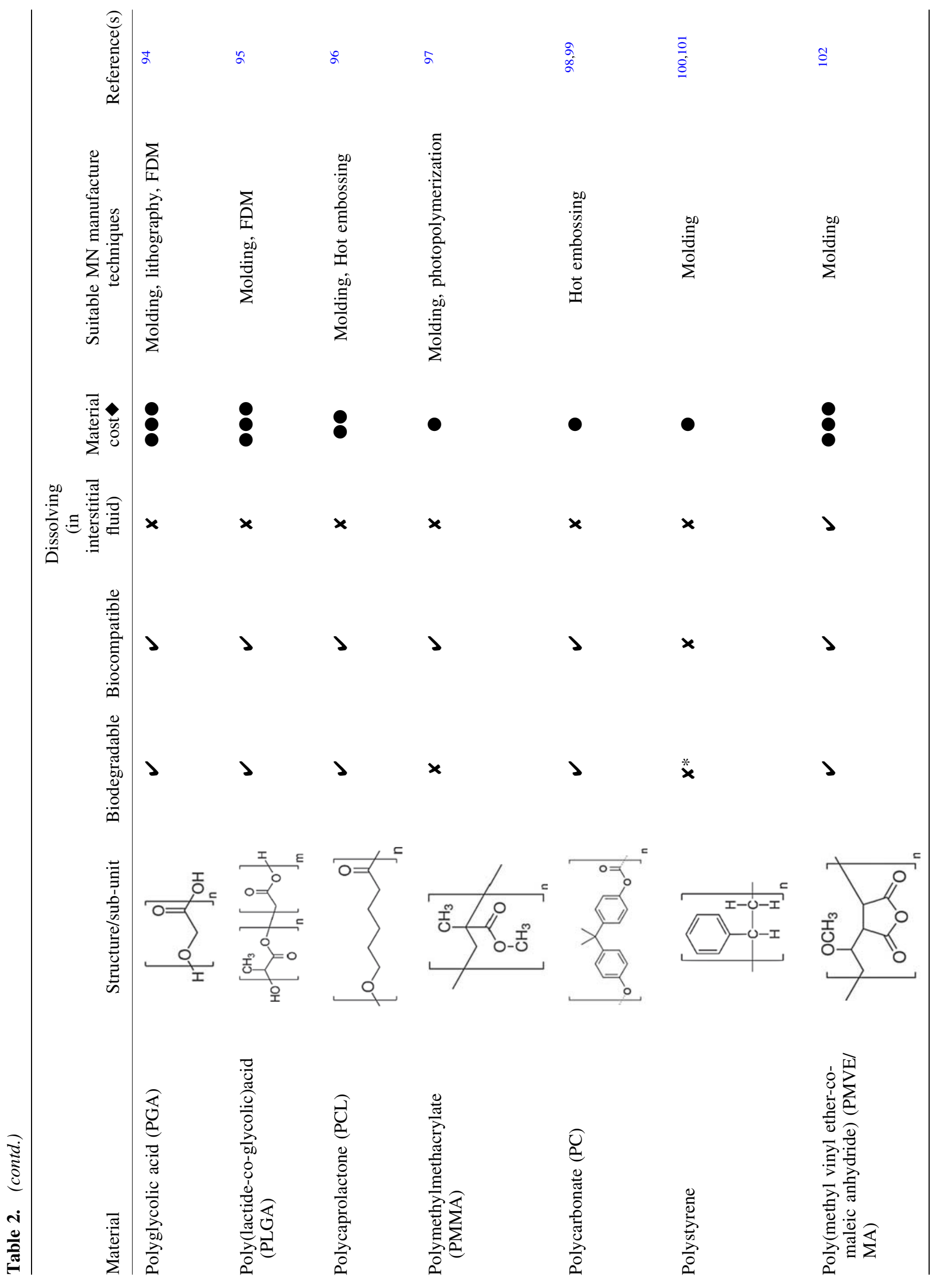




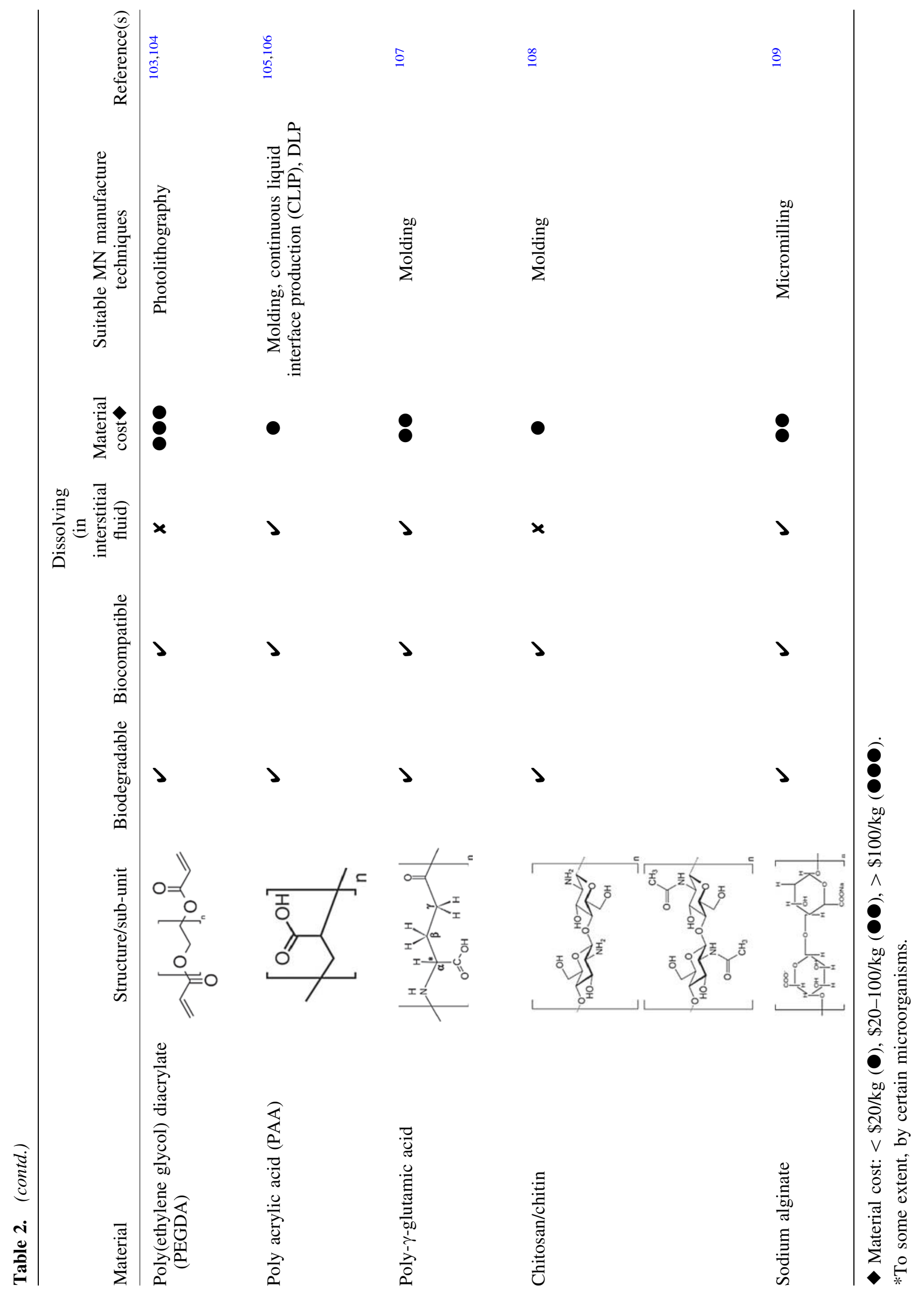


Table 3. A comparative assessment of various fabrication techniques reported for fabrication of MNs.

\begin{tabular}{|c|c|c|c|c|}
\hline Fabrication technique & Material(s) used & Advantages & Limitations in scale-up & References \\
\hline Micropipette pulling & Borosilicate glass & Cost-effective & $\begin{array}{l}\text { Excessive calibration } \\
\text { required; time- } \\
\text { consuming }\end{array}$ & 135,136 \\
\hline $\begin{array}{l}\text { Typical micromolding } \\
\text { (casting) }\end{array}$ & $\begin{array}{l}\text { Sodium alginate, PLGA, } \\
\text { Hyaluronic acid, } \\
\text { Gantrez, PVP, } \\
\text { PMMA, Zein, CMC, } \\
\text { starch, gelatin, } \\
\text { Oromocer }^{\circledR}\end{array}$ & $\begin{array}{l}\text { Cost-effective; } \\
\text { multiple } \\
\text { needles can be } \\
\text { produced from } \\
\text { same } \\
\text { micromold }\end{array}$ & $\begin{array}{l}\text { Wear and tear of molds } \\
\text { over time; } \\
\text { examination/cleaning of } \\
\text { molds between casting } \\
\text { cycles; complex MN } \\
\text { designs not achievable; } \\
\text { Drying processes may } \\
\text { take time; post- } \\
\text { processing required; } \\
\text { limited to } \\
\text { solid MN }\end{array}$ & $85,97,109,119,137-141$ \\
\hline Injection molding & $\begin{array}{l}\text { Polycarbonate, cyclic } \\
\text { olefin copolymer }\end{array}$ & $\begin{array}{l}\text { Low post- } \\
\text { processing }\end{array}$ & $\begin{array}{l}\text { Drying processes may take } \\
\text { time; wear and tear of } \\
\text { molds over time }\end{array}$ & 142,143 \\
\hline Hot embossing & PMMA, PLGA & $\begin{array}{l}\text { Low post- } \\
\text { processing }\end{array}$ & $\begin{array}{l}\text { temperature-sensitive } \\
\text { drugs cannot be } \\
\text { loaded }\end{array}$ & 144,145 \\
\hline Investment molding & $\begin{array}{l}\text { Cyclic olefin copolymer } \\
\left(\text { Ticona Topas }{ }^{\circledR}\right), \text { PLGA }\end{array}$ & $\begin{array}{l}\text { Hollow MN can } \\
\text { be prepared }\end{array}$ & MN design limitations & 143,146 \\
\hline $\begin{array}{l}\text { Filling mold cavities with } \\
\text { atomized spraying }\end{array}$ & PLGA, PVP & $\begin{array}{l}\text { High } \\
\text { temperatures } \\
\text { not needed; } \\
\text { viscosity } \\
\text { independent } \\
\text { spraying }\end{array}$ & Continuous process needed & 147 \\
\hline Photopolymerization & $\begin{array}{l}\text { PVP, PEG } 600 \\
\text { diacrylate, gelatin } \\
\text { methacryloyl, } \\
\text { methacrylate }\end{array}$ & $\begin{array}{l}\text { Higher strength } \\
\text { of needles } \\
\text { produced; } \\
\text { faster } \\
\text { dissolution } \\
\text { rates }\end{array}$ & $\begin{array}{l}\text { High cost of } \\
\text { photoinitiators; } \\
\text { Crosslinking conditions } \\
\text { may need to be } \\
\text { maintained }\end{array}$ & $148-151$ \\
\hline Stereolithography & $\begin{array}{l}\text { Gantrez, class I resin, } \\
\text { dental SG (formlabs) }\end{array}$ & $\begin{array}{l}\text { High precision; } \\
\text { fine detaining }\end{array}$ & $\begin{array}{l}\text { Material fragility; high- } \\
\text { cost machinery; mass } \\
\text { production not } \\
\text { possible }\end{array}$ & 152,153 \\
\hline Fused deposition modelling & PLA & $\begin{array}{l}\text { Cost-effective; } \\
\text { ease of } \\
\text { manufacture }\end{array}$ & $\begin{array}{l}\text { Limited material choices; } \\
\text { higher temperatures } \\
\text { needed }\end{array}$ & 93 \\
\hline Drawing lithography & SU-8, Maltose & $\begin{array}{l}\text { High aspect ratio } \\
\text { MN can be } \\
\text { prepared; } \\
\text { different MN } \\
\text { shapes } \\
\text { possible }\end{array}$ & $\begin{array}{l}\text { Limited material choices; } \\
\text { relatively high } \\
\text { temperatures used }\end{array}$ & 93 \\
\hline Photolithography + etching & $\begin{array}{l}\text { Poly ethylene glycol } \\
\text { diacrylate, CMC }\end{array}$ & $\begin{array}{l}\text { Efficient } \\
\text { process; } \\
\text { excellent } \\
\text { dimensional } \\
\text { control }\end{array}$ & $\begin{array}{l}\text { Expensive; clean and } \\
\text { darkroom requirement; } \\
\text { time-consuming; } \\
\text { material } \\
\text { limitations }\end{array}$ & 156,157 \\
\hline $\begin{array}{l}\text { Continuous liquid interface } \\
\text { production }\end{array}$ & $\begin{array}{l}\text { Trimethylolpropane } \\
\text { triacrylate }\end{array}$ & $\begin{array}{l}\text { Tunable } \\
\text { geometries; } \\
\text { mold- } \\
\text { independent; } \\
\text { single-step } \\
\text { process; fast }\end{array}$ & $\begin{array}{l}\text { Limited material options, } \\
\text { costly }\end{array}$ & 105 \\
\hline
\end{tabular}


Table 3. (contd.)

\begin{tabular}{|c|c|c|c|c|}
\hline Fabrication technique & Material(s) used & Advantages & Limitations in scale-up & References \\
\hline Two-photon polymerization & Ormocer $^{\circledR}$ & $\begin{array}{l}\text { Good resolution; } \\
\text { no cleanroom } \\
\text { requirement; } \\
\text { scalable }\end{array}$ & $\begin{array}{l}\text { Limited to photosensitive } \\
\text { materials }\end{array}$ & 158,159 \\
\hline Micromilling & PMMA, metals, SU-8 & $\begin{array}{l}\text { High precision; } \\
\text { good material } \\
\text { choices }\end{array}$ & $\begin{array}{l}\text { Costly; sophisticated } \\
\text { machinery; specific cuts } \\
\text { not possible }\end{array}$ & $160-162$ \\
\hline $\begin{array}{l}\text { Micromachining (laser } \\
\text { cutting, electroplating) }\end{array}$ & Stainless steel & $\begin{array}{l}\text { Complex MN } \\
\text { designs } \\
\text { achievable }\end{array}$ & $\begin{array}{l}\text { Costly; requires } \\
\text { sophisticated equipment; } \\
\text { limited to metals }\end{array}$ & 67,163 \\
\hline Droplet-born air blowing & $\begin{array}{l}\mathrm{CMC}, \\
\text { hyaluronic acid, PVP }\end{array}$ & $\begin{array}{l}\text { Simple and } \\
\text { efficient; Mild } \\
\text { operating } \\
\text { conditions } \\
\text { (temperature } \\
\text { and airflow); } \\
\text { Cost-effective; } \\
\text { minimum } \\
\text { post- } \\
\text { processing }\end{array}$ & $\begin{array}{l}\text { Only viscous preparations } \\
\text { can be used; limitations } \\
\text { to MN design }\end{array}$ & 67,163 \\
\hline
\end{tabular}

utilizing both $\mathrm{H}_{2} \mathrm{O}_{2}$ responsiveness and hypoxia conditions. ${ }^{127} \mathrm{H}_{2} \mathrm{O}_{2}$ labile linkers are generally used for this purpose. ${ }^{128}$ Figure $5 \mathrm{j}(1)$ shows PCL MNs loaded with silica-coated temperature-sensitive particles. The MNs are seen to disintegrate upon application of one cycle of NIR radiation in Figure $5 \mathrm{j}(2)$.

Transdermal delivery of micro and nanoparticles can be improved by $\mathrm{MN}$ assistance. The particles can be delivered through the conduits of hollow MNs, coated onto solid MNs or encapsulated within dissolving MNs. ${ }^{129-132}$ Figure 5c shows MNs completely prepared form PLA microparticles. Delivery of other therapeutics, especially proteins and vaccines can be enhanced by surface modifications of MNs. $\mathrm{pH}$ modification using pyridine on the surface of silicon MNs was shown to result in better loading and release of coated ovalbumin in the skin. ${ }^{133}$ Polyplex-based DNA vaccines were rapidly delivered using polycarbonate $\mathrm{MN}$ arrays coated with multiple polyelectrolyte layers of charge reversal $\mathrm{pH}$-responsive copolymers. ${ }^{134}$

\section{Manufacturing of MNs}

Manufacturing processes of MNs are dependent on various factors including material of construction. Various techniques for $\mathrm{MN}$ fabrication are listed in Table 3.

\subsection{Fabrication of silicon-based MNs}

The most commonly used technique for the fabrication of silicon-based MNs starts with lithography.
As shown in Figure 6, a photosensitive layer is coated onto a substrate (generally a silicon wafer with a silicon dioxide layer on top). A variety of materials can be coated onto the substrate based on the coating method used. A physical vapour deposition method is used to heat the material and condense its vapours onto the substrate. Alternatively, in chemical vapour deposition, material is deposited as a thin film

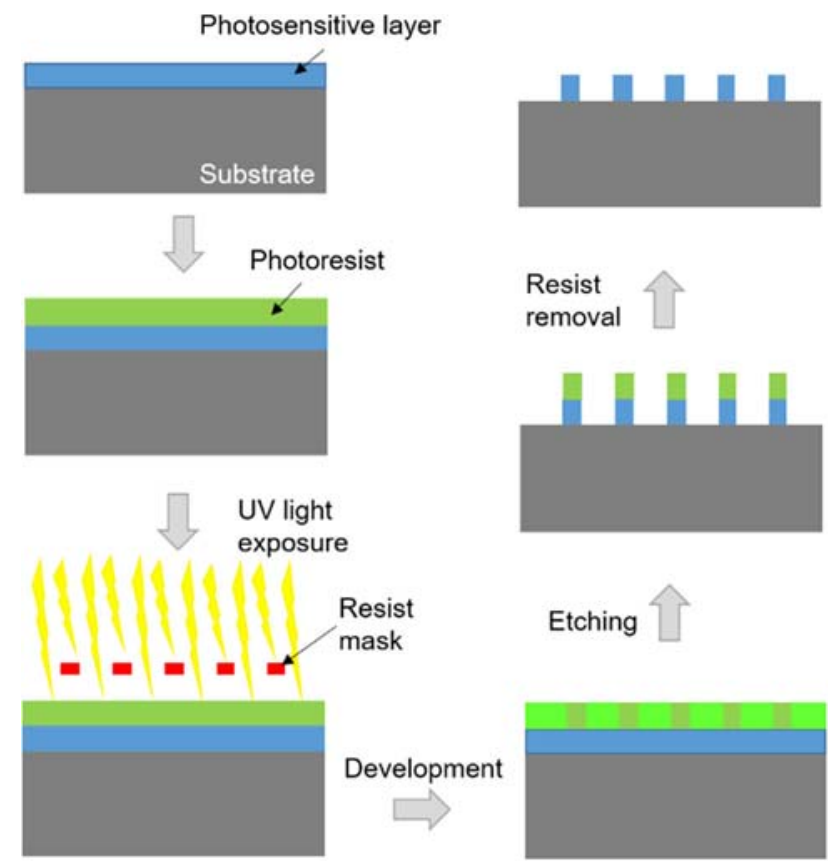

Figure 6. Steps in lithography/etching procedure for fabrication of silicon MNs. 
produced by chemical reaction between the hot substrate and inert-carrier gases in the chamber. A photoresist is layered on the silicon oxide substrate by spin coating. Spin coating ensures uniform thickness of coating. Any residual solvent on the spin-coated layer is removed by heating. The photoresist layer is illuminated by UV light through a mask. The mask behaves like a stencil not allowing UV radiation to pass through certain regions. This procedure allows near-perfect transfer of structure from mask to the photoresist layer. With UV exposure, the exposed regions of the mask are altered chemically and can now be easily solubilized and removed. A positive or negative photoresist can be developed based on requirements. With positive resists, UV illumination weakens the bonds allowing their easy removal, while in developing a negative resist, UV light strengthens the chemical bonds. The photolithographic process depends on thick photoresist polymer used. SU-8 and poly-methyl-methacrylate (PMMA) are versatile materials, which are used to produce a pattern for high-aspect-ratio microstructures. SU-8 can provide a sophisticated structure by controlling the light path and the focus, resulting in the production of solid tapered MNs and hollow polymer MNs. ${ }^{165}$

Following lithography, it is necessary to etch the oxide layer and even the substrate. For wet etching, the wafer is immersed in a liquid bath containing a chemical etchant to remove the desired material. Etchants generally used for silicon are potassium hydroxide $(\mathrm{KOH})$ and tetramethyl ammonium hydroxide (TMAH) ${ }^{166}$ Dry etching may be performed as reactive ion etching (RIE) or ion beam milling (IBM). In RIE, a plasma of reactive ions is created in a chamber and these ions are accelerated towards the material to be etched. In the case of IBM, inert ions are accelerated from a source to physically remove the material to be etched. Finally, an oxygen plasma treatment, called descumming is performed to remove the unwanted resist left behind.

\subsection{Fabrication of metal MNs}

The simplest way to fabricate metal-based MN arrays is by assembling hypodermic needles or wires. The length of the wire or tubing can be tuned as per enduser needs. Simple needle-based cosmetic devices, such as the Dermaroller consist of metal pins arranged on a cylindrical drum. MNs can be made in-plane using a lithographic/etching process and then bent at 90 degrees to create out-of-plane needles. Further, complex MN designs and shapes are prepared by laser metal cutting followed by electroplating (Figure 4e). Fabricating metal MN structures is time-consuming and requires sophisticated machinery and is thus a costly affair. However, the dimensional precision achieved with these processes is typically high.

\subsection{Fabrication of glass and ceramic MNs}

Glass MNs are an alternative to hollow metal MNs. Glass MN are generally fabricated by pulling borosilicate glass pipette using a micropipette puller. A length of glass tubing is heated at its centre and the two ends are drawn apart by toothed wheels are driven using a spring. The tips are bevelled at the required angle and cleaned using solvents. This method apart from time-consuming also requires exhausting calibration to achieve required glass thicknesses and lengths; thus it is not suitable for industrial applications. Ceramic MNs are typically prepared by micromolding with a ceramic slurry filled into mold cavities under vacuum followed by sintering at high temperatures.

\subsection{Fabrication of polymer MNs}

Molding is the most common technique for fabricating polymer MN. This is done via injection molding, hot embossing or micromolding as shown in Figure 7. Other techniques used to fabricate $\mathrm{MNs}$ include drawing lithography, laser micromachining or X-ray methods.

Molding typically involves a female mold which has cavities corresponding to the final MN structure that is intended to be achieved. These molds can be prepared using different materials, however, most commonly they are made from PDMS. PDMS molds are generally made from a master structure made of metal or silicon. PDMS offers transparency, short curing times, flexibility and good reproducibility in forming secondary structures and thus is a common choice of material. PDMS is inexpensive and a number of molds can be prepared and used at the same time. ${ }^{117}$ Alternatively, using a laser-based micromolding technique, silicon or metal-based female molds may be developed. Laser beams can be made to focus on concentrated areas leading to ablation at those spots. The laser power and illumination time can be digitally controlled to produce defined patterns in the material. ${ }^{118}$ This technique, however, requires sophisticated machinery and a number of molds to be produced for large scale manufacture, thus limiting its use in an industrial setup.

Carbohydrate MNs are also typically prepared using micromolding (Figure 7a). Sugars are dissolved or 


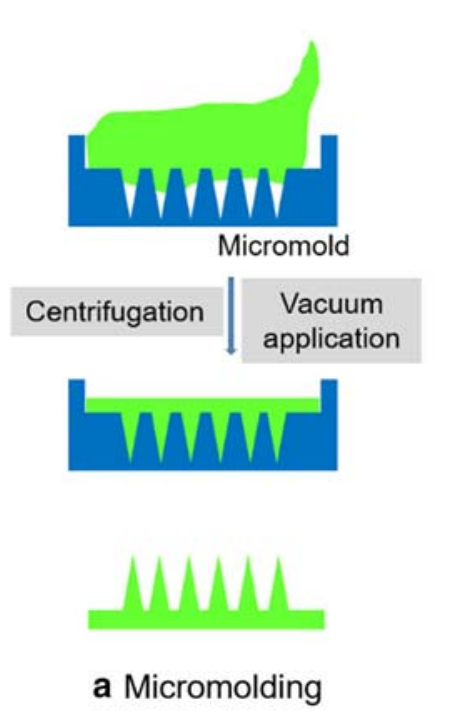

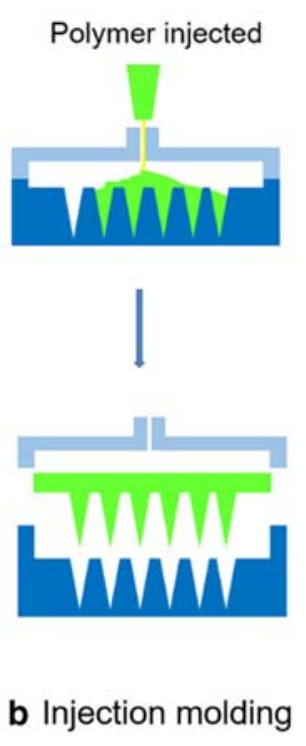

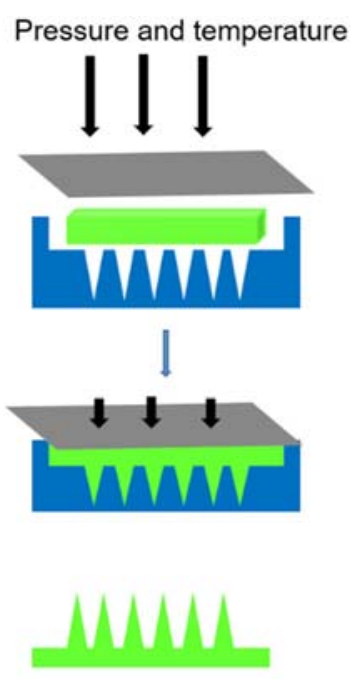

c Hot embossing

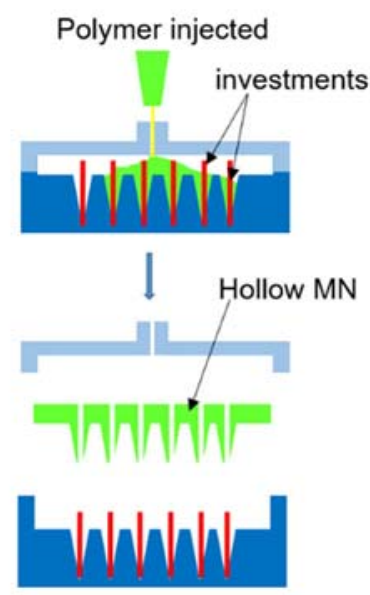

d Investment molding

Figure 7. Various casting and molding techniques used for the preparation of sugar and polymer MNs.

melted to viscous preparations and poured onto a mold followed by spin casting or vacuum application to fill the mold cavities. Sugars pose a challenge as they change color and caramelize at higher temperatures, and lead to a brittle end product. Also, high viscosities may create a flowability problem and entrap air bubbles during casting which may not be efficiently removed once the material starts to solidify. Maltose $\mathrm{MNs}$ are generally prepared by heating maltose to $140{ }^{\circ} \mathrm{C}$ and filling in PDMS molds under vacuum. Additionally, thermolabile molecules may not be suitable for loading with carbohydrates due to hightemperature processing. Martin et al., attempted to address the problem with loading thermolabile drugs by preparing sugar MNs at low temperatures (Figure $5 b$ ). This was done by dehydrating sugar combinations and generating solid amorphous sugar glasses with low water content for molding under vacuum. ${ }^{84}$ Sugar MNs dissolve quickly even in atmospheric humidity and need to be stored in moisture control packages.

Apart from regular casting followed by vacuum application or spinning, injection molding or hot embossing may be used to prepare polymeric MNs. Lutton and co-workers presented injection moulded siloxane molds to prepare hydrogel MNs by either application of a roller or centrifugation after filling the mold with polymer. ${ }^{167}$ Polymers with relatively lower melting points can be fabricated into MNs by hot embossing (Figure 7c). Polycarbonate MNs were prepared by stacking a plastic sheet onto the silicone rubber mold. The stack was pressed together at $170{ }^{\circ} \mathrm{C}$ maintaining enough load to fill in the mold cavities. ${ }^{168}$
Molding offers a cost-effective and scalable technique for the fabrication of polymeric MNs. However, based on polymer properties, solvents used, temperature and pressure conditions, the siloxane molds undergo wear and tear. The wear and tear may be significant to affect the final MN structures. It is also important to remove any clogged material in the mold cavities between different casting cycles. These shortcomings may hinder efficient use of micromolding processes. To that end, Lee and co-workers suggested preparation of maltose $\mathrm{MNs}$ by drawing lithography. Patterned stainless steel pillars were attached with a syringe pump. Maltose was melted at $110{ }^{\circ} \mathrm{C}$ in water and coated onto a circular steel plate. The plate was placed in contact with the steel pillars and cooled down to $\mathrm{T}_{\mathrm{g}}\left(95^{\circ} \mathrm{C}\right)$. The pillars were axially drawn at controlled speeds and temperatures (Figure 8). Varying the temperature and speed resulted in needles of different shapes, with high aspect ratios and sharp tips. ${ }^{155}$

A number of polymers including PVA, PVP, Gantrez, gelatin, collagen, and zein, have been fabricated into MNs using the simple molding techniques. Few procedures involve molding followed by in-situ polymerization to result in final MNs. Sullivan and co-workers added vinyl pyrrolidone to PDMS molds where polymerization was initiated by added free radical initiator azobisisobutyronitrile when placed under UV light. The resulting needles showed greater fracture forces and faster dissolution. In a similar study, MNs were prepared by polymerization of methacrylic acid. ${ }^{151}$

Molding processes are generally used to make solid MNs, however, hollow MNs can also be prepared by 


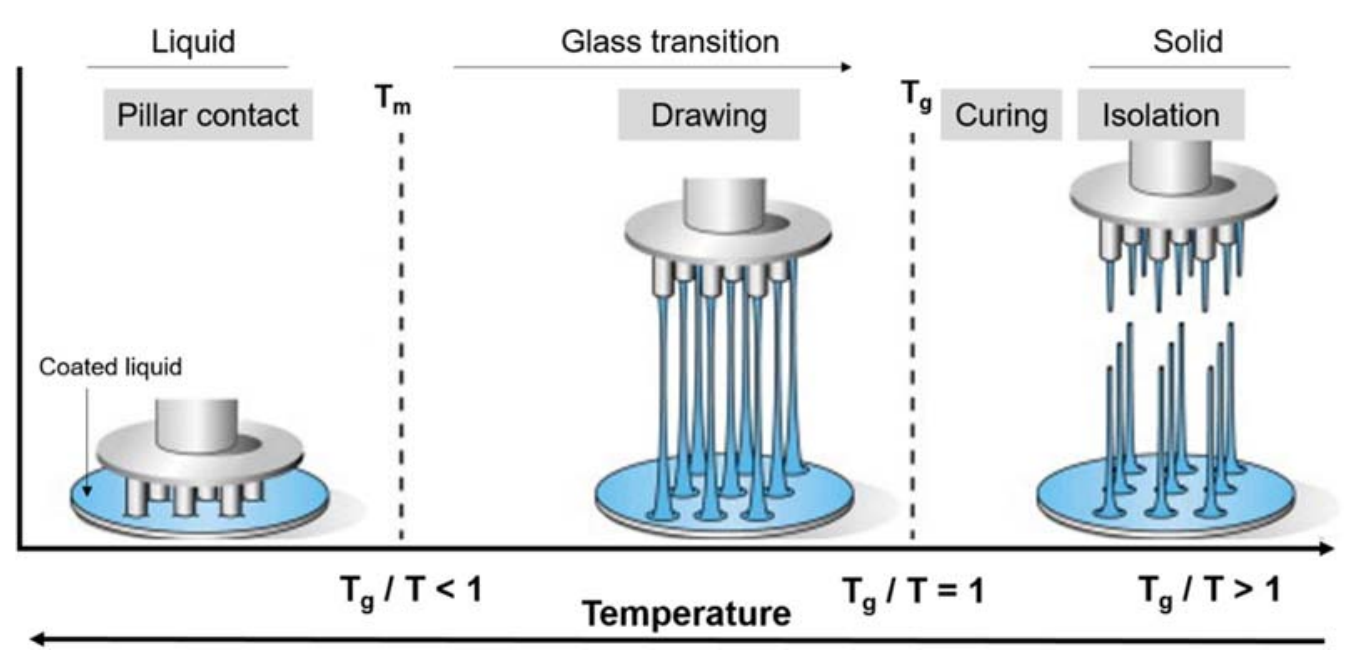

Figure 8. Schematic representation of drawing lithographic process. Cooling of melted liquid polymer to $\mathrm{T}_{\mathrm{g}}$ from higher temperature significantly increases its viscosity turning it into a glassy liquid and eventually into solid structures, which are cured and isolated. $\mathrm{T}_{\mathrm{m}}-$ melting temperature; $\mathrm{T}_{\mathrm{g}}-$ glass transition temperature. Image modified with permission from. ${ }^{154}$

using investment molding which combines injection molding and casting (Figure 7d). A cyclic olefin copolymer (Ticona Topas ${ }^{\circledR}$ ) was injection molded around a $32 \mu \mathrm{m}$ diameter $\mathrm{Al}$ wire. The wire was dissolved later by a liquid $\mathrm{Al}$ etchant to produce hollow in-plane polymeric MNs. ${ }^{143}$ Various attempts have been made to fabricate complex $\mathrm{MN}$ designs with ease using polymers. In a noteworthy study, Park and coworkers filled MN molds with polymeric microparticles against polymer solutions or melts. Micron-sized particles were prepared from PLA, PGA and PLGA by spray drying or emulsification methods. PLA particles were forced into the mold cavities by pressing a male mold over the cavities. The filled mold was 'cured' by applying ultrasonic energy over the PLA particle cake through another PDMS layer. The mold was cooled to remove the formed $\mathrm{MN}$ array (Figure 5c). PLGA particles were cast but in different layers and in combination with other polymers to produce layered MNs. Using PLGA and PLA particles, the researchers presented separable tip needles composed of PLGA containing Vitamin B over PLA shafts. ${ }^{117}$ Figure $5 f$ shows microparticles concentrated at the tip of a PLGA MNs. The same research group also reported separable arrowhead needles prepared from PLA, PVP, and PVA assembled as sharp needles over metal shafts (Figure $5 \mathrm{~h}$ ). The needles could be inserted into the skin and the arrowheads could be left in the skin to dissolve. $^{121}$

A recently patented technology called droplet-airblowing allows the preparation of dissolving MNs at mild conditions (low temperatures and minimum postprocessing) thus allowing loading of sensitive cargo such as vaccines or genetic material. Polymer solutions are placed as equidistant specific volume drops on a sheet. Another sheet is lowered down and made to contact the viscous drops. This is followed by pulling away of sheets at controlled speeds. As the sheets pull away, the drop begins to converge between the two sheets forming a thin filament as the sheets are pulled apart. Once the required polymer elongation is achieved, air is blown through the sheets at controlled speed to dry out the polymer before separating the sheets with formed MNs. This technique has been used to prepare MNs using hyaluronic acid, PVP, CMC among other polymers and is also available for commercial use. ${ }^{164,169}$

\section{$3.53 D$ printing of $M N s$}

3D printing has emerged as a technique for fabrication of MNs with several recently published reports describing its potential. 3D printing is used in three different ways in $\mathrm{MN}$ development: 1) To develop male master molds; 2) coating material or drugs onto previously prepared MNs; 3) printing complete $\mathrm{MN}$ structures using 3D printing. Our group has developed 3D printed master molds which were used to prepare polymeric MNs. Acrylobutadiene styrene (ABS), a thermoplastic photopolymer was used to print molds using polyjet $3 \mathrm{D}$ printer. ${ }^{85}$ Layers of ABS are jetted onto the platform and cured instantly by UV light. The jetting is based on a CAD design previously imported into the $3 \mathrm{D}$ printer. The fine layers of ABS allow for good dimensional precision and needles with sharp tips can be generated. A simple post-curing process removes all supporting material from the design; 

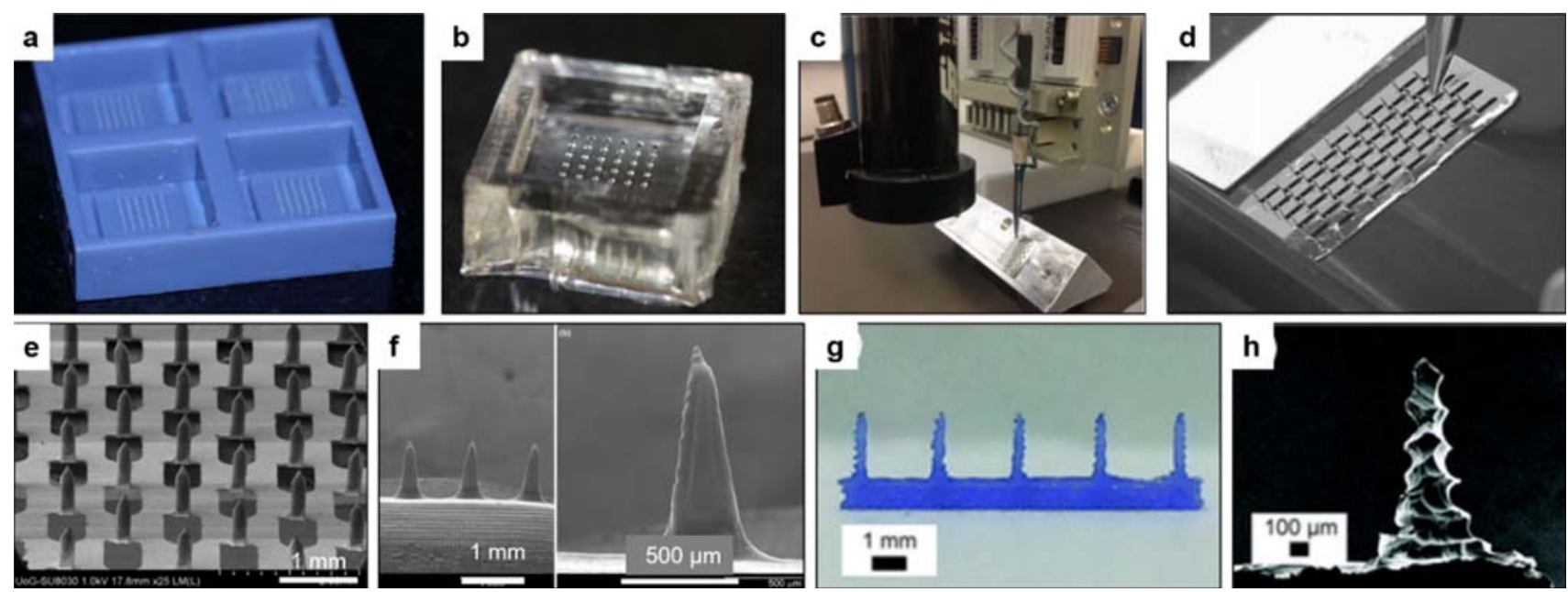

Figure 9. 3D printing of MNs. Image of an ABS master mold (a) and the corresponding PDMS mold (b) developed. (b) A piezoelectric nozzle printing coating formulation on the stainless-steel MN array (c) with arrays placed at 45 degrees (d). SEM image of inkjet-printed 5-FU stainless steel MNs (e). SEM images of inkjet-printed miconazole-loaded Gantrez ${ }^{\circledR}$ AN 169 BF MNs (f). Biodegradable PLA MNs printed using FDM (g and h), ${ }^{\circ}$ The Royal Society of Chemistry (2018). Images reprinted with permission from. ${ }^{93,170,171}$

however, this could be a tedious process if complex designs are to be printed. Figure $9 \mathrm{a}$ and $9 \mathrm{~b}$ show a 3D printed ABS master mold and the corresponding PDMS mold, respectively.

Using inkjet printing, metals, polymers or drugs can be coated onto preformed needles. Boehm and coworkers report coating of Gantrez ${ }^{\circledR}$ needles with antifungal agents, amphotericin B or miconazole. ${ }^{170}$ Amphotericin B was dissolved in DMSO and loaded in the inkjet cartridge reservoir bag of a DIMATIX material printer. The cartridge dispensed amphotericin solution at a volume of $10 \mathrm{pL}$. The MNs were placed parallel to the printing platen to deposit the drug solution. Keeping the parameters such as drop spacing, density, voltage, cartridge angle and cartridge temperature constant, fifteen layers of drug solution were deposited. Each array could be loaded with $10.4 \mu \mathrm{g}$ of amphotericin. ${ }^{152}$ The process resulted in MNs with a smooth texture as shown in Figure 9f. Uddin et al., report inkjet coating of metal MNs with three anticancer molecules viz. 5-fluororacil (5FU), curcumin and cisplatin. Drug solutions were jetted onto stainless steel MNs placed at an angle of 45 degrees (Figure 9c and 9d) with $300 \mathrm{pL}$ droplets. ${ }^{171}$ 5-FU coated steel needles are seen in Figure 9e. The same coating technique was extended to understand coating of insulin onto metal MNs. ${ }^{172}$

Building MNs using 3D printing has been attempted recently with different materials and methods. Allen and co-workers report a 'drop-on-demand' technique for filling PDMS micromolds with polymer solutions. The authors argue that the mold cavity filling procedures (vacuum application, centrifugation) with micromolding that ensure no air pockets are formed in the MNs, are not scalable to manufacturing scale. A piezo dispensing technique was used to drop picolitres of polymer solution as droplets into micromolds. Formed MNs had a good surface finish and could also be formed as bilayered structures containing the drug in the tips. ${ }^{173}$ Materials which polymerize upon exposure to UV light are good candidates for 3D printing into MNs provided they are biocompatible. Stereolithography (SLA) and Digital Light Processing (DLP) are two techniques used for these purposes. Use of SLA to draw MNs has been discussed in the previous sections. DLP is faster than SLA as it cures materials in layered cross-sections. Gittard et al., report acrylate-based polymer needles for wound healing application fabricated using DLP. ${ }^{174}$

Fused deposition modelling allows material melts to be $3 \mathrm{D}$ printed. This is an inexpensive technique, with starter printer models available for home-use. Materials need to be available as filaments which are melted when introduced into the printer and fused in a controlled fashion according to input CAD design. Several biomaterials, such as PLA, PGA, PCL, PVA and PLGA can be used as FDM substrates. Using FDM technology and a post-process chemical etching procedure, PLA MNs with tips as small as 1 micron could be obtained (Figure $9 \mathrm{~g}$ and $9 \mathrm{~h}$ ). ${ }^{93}$

Use of 3D printing to develop MNs is limited by the materials that can be used for the 3D printing technology at hand. Only photopolymers can be printed using SLA or DLP, while FDM requires thermoplastic 
filaments. The photoinitiators used in SLA may be toxic whereas FDM requires high temperatures for filament melting and generally has a low print resolution. ${ }^{175} \mathrm{~A}$ few materials such as Gantrez ${ }^{\circledR}$ or PVA can be used to form dissolvable MNs using FDM. It is not possible to process materials which are thermosensitive, such as thermolabile drugs, proteins or genetic material using FDM. PLA is an excellent material for MN fabrication by FDM, but its slow degradability limits its pharmaceutical use.

\section{Biocompatibility, biodegradability and stability considerations}

As MNs penetrate biological barriers, they come in contact with viable tissue. Thus, it is imperative that the chosen MN material is biocompatible. Biocompatible materials do not produce a toxic or immunological response when exposed to the body or bodily fluids. If a material degrades in tissue, the degradation of products and by-products should be nontoxic. Accumulation of material in the tissues with slow degradation is also undesirable. Since the temperature or $\mathrm{pH}$ conditions in the biological system are different from ambient conditions, materials may behave differently when in contact with biological tissue. Thus, it is important to ascertain the compatibility of material within the conditions it will be subjected to. It is also required to ascertain the stability of $\mathrm{MN}$ material of construction in terms of the manufacturing method and conditions, storage conditions, and most importantly, compatibility with the molecule(s) loaded.

\subsection{Silicon and silica glass}

Silicon is widely used in the development of implantable biomedical devices including neural prostheses, drug delivery systems, and chemical probes. The biocompatibility of silicon has been studied over the last few years but enough evidence guaranteeing their biocompatibility is not established. It has been shown that nanoporous silicon does not exhibit significant toxicity which has led to its extensive used for drug delivery as silica nanoparticles. ${ }^{176}$ Silicon MNs have been studied for drug delivery of a variety of drug molecules. Since silicon and silica glass are relatively brittle materials, their chipping or breaking off in the tissue after application poses a hazard. Researchers report a coating of inert metal such as gold on the silicon MNs will improve its biocompatibility. ${ }^{177}$ MicronJet $^{\circledR}$, one of the two
FDA-approved MN-based devices in the market comprises of silicon MNs. ${ }^{2}$ As most silicon MNs are inserted for shorter durations, it will be interesting to look at long term contact of silicon MNs with tissue during long applications. Borosilicate glass is an inert material that is used for MN fabrication. It is, however, important to consider any adsorption of molecules, especially proteins that may happen on the glass surface. Most glass MNs are hollow and are designed for quick insertion into the skin or for short-term drug infusions. MNs fabricated out of glass have also been tested for drug delivery across scleral tissue. Studies for long term contact of silicon or glass implants/ needles with biological tissues are required to ascertain the long-term use of these materials.

\subsection{Metals}

The most frequently used biocompatible metals in biomedical applications are stainless steels, cobaltchromium alloys, and titanium and its alloys. Surgical stainless steel $316 \mathrm{~L}$ is the most commonly used grade of steel for use in biocompatible devices. Stability of metal structures is dependent on the environmental conditions are they are placed in. Corrosion of metals is based on oxygen, moisture and $\mathrm{pH}$ conditions which vary greatly outside and inside the human body. As a result of oxidation and acidic erosion, a metal implant that does well in one state of the body may still experience an undesirable level of corrosion in another. Metal corrosion is advanced in the presence of aqueous ions. Most fluids in the human body have solutions composed majorly of $\mathrm{Na}+, \mathrm{Cl}-, 0.9 \%$ saline and other trace ions with a number of amino acids and soluble proteins in normal conditions. These solutions have near-neutral $\mathrm{pH}$ values in the range of 7.2-7.4 at $37^{\circ} \mathrm{C}$. In certain physiological conditions such as inflammation, $\mathrm{pH}$ values of the body fluid may drop. The body ion deposition in the body in combination with other factors such as blood pressures may influence the stability of a metal implant. Even at stressful body conditions, a low release of metal ions from metal MN should be ensured. ${ }^{178}$

Stainless steel offers good biocompatibility but is susceptible to corrosion upon prolonged use. Upon corrosion, stainless steel releases nickel ions, which may contribute to cancer development. Other metals such as titanium alloys provide superior strength and anti-corrosive nature for biomedical use. However, a few reports of allergic reactions with first-generation titanium alloys are reported. There is a lack of data for long-term clinical usage of titanium alloys. Other 
metals that have been used for MN fabrication include platinum, palladium, nickel, silver and gold. Gold and platinum coating on MNs have been shown to improve the biocompatibility, but they present higher costs.

\subsection{Ceramics}

Bioinert ceramics, termed as bioceramics are used in the manufacture of prostheses. Alumina has been used for bone and dental implants for over two decades, thus its biocompatibility is well documented. Of all ceramics, $\mathrm{Al}_{2} \mathrm{O}_{3}$ and $\mathrm{ZrO}_{2}$ have superior resistance to wear and tear. ${ }^{179} \mathrm{~A}$ few reports of toxicity due to risk of aluminium release upon long term usage are documented, however, alumina MNs are expected to not pose any toxicity issues as their contact time with viable tissue would be limited. Silicon nitride is now approved in terms of biocompatibility and expected to develop in orthopaedics. ${ }^{180}$ Calcium phosphate, which is naturally also naturally present in bone has been established as biocompatible ceramic for surgical implants. The Ca:P ratio determines the acidity and solubility of calcium phosphates and the biocompatibility may be different with different ratios. Hydroxyapatite $\mathrm{Ca}_{10}\left(\mathrm{PO}_{4}\right)_{6}(\mathrm{OH})_{2}$ has shown to be bioactive and bioresorbable. Synthetic hydroxyapatite has been shown to produce no local or systemic toxicity, no inflammation, and no foreign body response. ${ }^{181,182}$ Many studies have demonstrated Ormocer $^{\circledR}$ as a potential biocompatible ceramic for $\mathrm{MN}$ fabrication. Ovsianikov et al. demonstrated that this material does not adversely affect the growth of human epidermal keratinocytes, a major cellular component of the skin. ${ }^{183}$

\subsection{Carbohydrates}

Natural sugars are approved as stabilizers and cryoprotectants. Of all sugars, maltose has been most studied for the fabrication of MNs. Other sugars like trehalose and galactose are also approved for pharmaceutical use, however, their use for MN fabrication is limited. If meant for diagnostic applications, sugar MN may interfere with diagnosis especially if blood glucose measurement is the intention. Polysaccharides are biodegradable and their biological activity can be easily tuned. Most polysaccharide MNs disintegrate in the skin to release the payload. If absorbed in the skin, they can be gradually eliminated by the kidney. Most polysaccharides in drug delivery are derived from natural sources, alginate and chitin, extracted from algae and crab shells respectively, find broad uses in drug delivery. Chitin is biocompatible and is degraded into non-toxic residues by lysozyme through the hydrolysis of the acetylated residues. ${ }^{184}$ Moreover, recent studies have indicated that chitosan and their derivatives are novel scaffold materials for tissue engineering and promising non-viral vectors for gene delivery. ${ }^{185}$ Alginate is an excellent material of choice for fabrication of MNs as it forms hydrogels at mild $\mathrm{pH}$ and temperature, is non-toxic, biocompatible, biodegradable, inexpensive and abundantly available in nature. Additionally, alginate is more compatible with sterilization procedures. ${ }^{186}$ Carboxymethyl cellulose and hydroxypropyl cellulose, both of which are biocompatible and biodegradable are most important cellulose derivatives for use in drug delivery. In general, the rate of degradation of celluloses is governed by their molecular weight and degree of acetylation.

Hyaluronic acid is a major component of the extracellular matrix and is found in skin, cartilage, bone, and many other tissues. It is commercially used in wound dressing products and has been widely studied for MN fabrication. ${ }^{187,188}$ Microhyala $^{\circledR}$, a hyaluronic acid-based $\mathrm{MN}$ array is marketed for cosmetic use. Hyaluronic acid MN dissolves rapidly in interstitial fluid and is degraded within the body by free radicals found in the extracellular matrix, and lysosomal enzymes. ${ }^{189}$ Dextran is another high molecular weight polysaccharide used in biomedical applications and $\mathrm{MN}$ fabrication. It is biocompatible, biodegradable, lacks nonspecific cell binding and is resistant to protein adsorption. Dextran is degraded by amylases and cleared via the kidney. ${ }^{6}$ Other polysaccharides such as starch-based amylopectin although biocompatible are not a frequent choice for $\mathrm{MN}$ fabrication as they do not degrade easily.

\subsection{Polymers}

Most polymers used for drug delivery are biocompatible. Natural protein-based polymers such as collagen, gelatin, or zein are approved for different pharmaceutical usages. Collagen is largely biodegradable and biocompatible; however, a few reports indicate poor stability upon swelling in vivo, nonspecific immune reactions and tissue reactions. Collagen swells upon contact with aqueous media but can only be digested by specific collagenases and pepsin-cleaving enzymes. ${ }^{190}$ Gelatin, irreversibly hydrolysed form of collagen, is a common constituent in food additives and soft capsules. Gelatin in combination with other materials is also studied for $\mathrm{MN}$ fabrication. ${ }^{75,76}$ Due to the absence of aromatic groups 
(no Tyr and Trp, and low Phe), gelatin is not antigenic. Like collagen, gelatin also degrades after swelling by the action of specific peptide cleaving enzymes. Zein is a GRAS substance and has shown to possess good biocompatibility, low/no immunogenicity and potential for development as bone tissue engineering metal. ${ }^{191,192}$ MNs made from zein are shown in Figure 5e. Silk has been studied for preparation of MNs, however, as an unconventional material, studies commenting on its biocompatibility status are limited.

Semisynthetic and synthetic polymers are used in the field of drug delivery including fabrication of MNs. SU-8 is relatively cheap and does not require complex machinery for processing. A certain level of biocompatibility of SU-8 is established, however, further studies are warranted. ${ }^{193,194}$ Also, SU-8 does not disintegrate in the skin and is not biodegradable. SU-8 MNs can be seen in Figure 5g.

Aliphatic polyesters are biocompatible and degrade once inserted into the skin. The degradation times of these polymers are governed by their molecular weight, crystallinity, surface area exposed to biological tissue and ratio of monomers (in case of copolymers such as PLGA). PGA is more hydrophilic than PLA and degrades faster, as does PLGA with a higher concentration of glycolide. Aliphatic polyesters degrade hydrolytically forming naturally occurring lactic acid. PLA, PGA, and PLGA alone and in combination with other materials such as hydroxyapatite have been used for bone regeneration and fabrication of MNs. ${ }^{195-197}$ Although, these polymers are accepted as biocompatible, there are reports for delayed immunological inflammatory responses with the use of PGA and PLA based implants. This is attributed to the production of acidic degradation products, however, the risk could be mitigated with the use of alkaline salts or inflammatory mediators. ${ }^{198,199}$ PCL is biocompatible and biodegradable polyester used for $\mathrm{MN}$ fabrication. ${ }^{105,200,201}$ PCL can also degrade hydrolytically, however, the degradation is much slower than that of PGA. ${ }^{202}$ The degradation of PCL can also be enzyme-mediated, where low molecular weight PCL remains may cause adverse immunological reactions. ${ }^{202}$ PCL has exceptional thermal stability and a low melting point allowing for easy $\mathrm{MN}$ fabrication using micromolding or 3D printing. The stability, biocompatibility and biodegradability of PCL is extensively studied as PCL based implantable Levonorgestrel releasing contraceptive device, Capronor ${ }^{\circledR}$ is commercially available. ${ }^{203}$

Polycarbonates and PMMA are both biocompatible materials reported for MN fabrication. PMMA finds application as a constituent in bone fillers and bone cements, and intraocular lenses. ${ }^{204}$ Polycarbonate (PC) polymers possess can be made into sheets, fibres, tubes or complex shapes and the material transparency they provide finds usage in the fabrication of medical apparatus, such as syringes, artery cannulas, or blood filter housings. PC is biodegradable but degrades slowly, while PMMA is not biodegradable. Bisphenol$\mathrm{A}$ is released upon degradation of PC and is reported to cause hormonal side-effects and cancer. ${ }^{205}$ Additionally, polycarbonates are stable against a variety of sterilization techniques (ethylene oxide, gamma and electron beam irradiation or steam autoclaving) making them one of the sought-after materials in medical device fabrication.

PMVE/MA finds use in the medical and pharmaceutical field as bioadhesives, thickening agents, and film-forming agents. ${ }^{206}$ Marketed by Ashland with the market Gantrez ${ }^{\circledR}$, these polymers have been used to prepare biocompatible micro and nanoparticles for drug delivery applications. ${ }^{207}$ Gantrez has shown to be relatively nontoxic with oral toxicity tests $\left(\mathrm{LD}_{50}\right.$ of $8-9 \mathrm{~g} / \mathrm{kg}$ ) and has also shown a relative lack of toxic effects on other organs. Few other studies discuss the biocompatibility of these polymers, however extensive studies are limited. Calo et al., report Gantrez based cryogels for wound care. These PVA-Gantrez cryogels demonstrated excellent biocompatibility against human dermal fibroblasts and adhered to wounds soothing the inflamed skin. ${ }^{208}$ Similar tests performed for PMVE/MA MN arrays suggested good biocompatibility of the system. ${ }^{102}$ The anhydride upon contact with water slowly transforms into free acid, which is freely water-soluble.

PVA, essentially made by hydrolysis of polyvinyl acetate is a hydrophilic, biodegradable and biocompatible synthetic polymer. It finds use in regenerative medicine, tissue engineering, fabrication of ocular inserts and soft contact lenses, and wound healing. ${ }^{209,210}$ All grades of PVA are hydrophilic, with solubility decreasing with increase in molecular weights. A large number of studies have established PVA as a biocompatible, non-toxic, non-carcinogenic, non-immunogenic and inert polymer. ${ }^{21}$ It gets hydrolysed quickly and degraded in the body. The only concern with the use of PVA is irreversible thermal gelling and loss of transparency upon longstanding. Also, cross-linkers used for PVA such as glutaraldehyde, formaldehyde or hexamethylene diisocyanate may reduce the inherent biocompatibility of PVA. ${ }^{209}$ As PVA is highly hydrophilic, it also takes up moisture quickly and becoming soft compromising the mechanical strength of structures. PVA is commonly used in combination with PVP for drug delivery 
applications. PVP is made of repeating units of monomer $\mathrm{N}$-vinylpyrrolidone. PVP is highly watersoluble taking up to $40 \%$ of its weight in moisture making it suitable for applications such as a superdisintegrant in fast dissolving tablets or as a plasma expander for trauma victims. PVP is used as a tablet binder or pore former, film-forming agent for tablet coatings or coating of medical devices, or as an excipient in powders, syrups, and parenteral formulations. PVP has low oral and transdermal toxicity, is hemocompatible and physiologically inactive. ${ }^{212}$ PVP is non-immunogenic and non-carcinogenic and has been studied for delivery of vaccines and genetic material. $^{213,214}$

\section{Sterilization of MNs}

MNs penetrate the epidermis and the dermis which inherently are sterile areas of the body. Thus, it is important to ensure that the MNs do not transfer any bioburden into the body during their application. Depending on the size of MNs and depth of penetration in tissue intended, regulatory bodies may require complete sterilization data before clinical trial or market approval. Using an in vitro setup, we have previously shown that application of MNs on skin had a significantly lower transfer of microorganisms into the body against a single hypodermic needle puncture, however, this is true for MNs which have been sterilized prior to application. Without doubt, MNs meant for application to the eye or internal organs of the body, or MNs which dissolve completely into the skin will have to completely sterile. The material of fabrication of MNs is a key contributor for choosing a sterilization method. Glass, metal and silicon MNs are easy to sterilize using a variety of procedures such as dry heat sterilization, moist heat sterilization, gamma radiation, etc. However, if these MNs are coated with molecules, sterilization processes may affect their structure and stability. MNs prepared using carbohydrates or polymers are difficult to sterilize as most of these materials cannot sustain high temperatures without undergoing structural changes. A few recent reports discuss sterile manufacture of MNs loaded with different actives. McCrudden and co-workers investigated the effect of different endpoint sterilization procedures (steam sterilization, dry heat sterilization and gamma radiation) for dissolving and hydrogelforming $\mathrm{MN}^{215}$ Ovalbumin and ibuprofen were model drugs incorporated in lyophilized wafers (prepared with different sugars and gelatin) placed over MNs prepared from PMVE/MA or loaded into the matrix for dissolving MN. Effectiveness of sterilization and $\mathrm{MN}$ stability after sterilization was evaluated by endotoxin quantitation, microbial assays, drug release studies and MN strength estimation. No bioburden was observed in the drug wafers or MN. Also, low endotoxin levels were observed. MN and drug wafers were unstable after both dry and moist heat sterilization. A Gamma radiation dose of $25 \mathrm{kGy}$ did not affect hydrogelforming $\mathrm{MN}$ but damaged the structure of ovalbumin and altered the appearance and drug release form ibuprofen loaded dissolving $\mathrm{MN}$. With gamma radiation sterilization, ovalbumin content in dissolving MN reduced from $101 \%$ recovery to about $58 \%$. The efficiency of gamma radiation for end-point radiation sterilization was also demonstrated by ascorbic acid 2-glucoside loaded hyaluronic acid dissolving MNs. Kim and co-workers found that electron beam maintained ascorbic acid activity post sterilization while loss of activity was seen with $\gamma$-ray irradiation (40 kGy). ${ }^{216}$ Endpoint sterilization is preferable for $\mathrm{MN}$ sterilization as running an aseptic manufacturing process is both complex and costly. ${ }^{217}$ As an alternative to sterilization procedures, Garcia and coworkers report a self-sterilizing $\mathrm{MN}$ array patch. Silver nanoparticles embedded in CMC MNs were used as antimicrobial agent. The authors suggest that the use of silver nanoparticles in MNs will keep the pores created by MNs bacteria-free until the skin is completely healed. $^{218}$

\section{Conclusions}

MNs have transformed the field of transdermal drug delivery from simple skin patches to point-of-care devices. The evolution of MNs as a drug delivery technique has been exponentially rapid with two MN devices already in the market for clinical use and a large number in clinical trials. The material of construction has emerged as an important factor in the design and development of MNs. Different materials present different advantages and challenges to $\mathrm{MN}$ designing, fabrication and drug loading. The drug delivery landscape has seen a major shift from simple solid metal MNs to dissolving needles which can also administer 'on-demand' therapeutics. This has largely been possible due to the advancements in material science.

Application of materials for biomedical usage requires a biocompatibility assessment. This review comments on the biocompatibility of various materials 
available for $\mathrm{MN}$ fabrication. While metals and silicon present inertness and low immunogenicity for $\mathrm{MN}$ usage, they do not dissolve or degrade and may leave sharps in the body. On the other hand, polymer MNs dissolve within the body to release the payload. Most polymers used for MN fabrication are safe for usage but may not degrade quickly accumulating in the body over multiple applications. Further, a few natural polymers may elicit unwanted immunological reactions. A number of clinical trials are ongoing for the safety assessment of both placebo and drug-loaded polymer MNs. A quick application of MNs, such as for vaccination, may not present a threat, but it is essential to assess the long-term biocompatibility of MNs patches intended to be used for hours to days.

MN fabrication techniques have become more precise and robust with lithographic and molding as the most common choices of fabrication. Micromolding presents a simple and cost-effective technique for fabrication of polymer and sugar MNs but suffers from disadvantages such as high drying times or post-processing, limiting its scalability potential. 3D printing has emerged as a new fabrication technique for MNs. Although still in its infancy, a number of MN designs have already been reported with the use of 3D printing. Most commonly used 3D printing technique include inkjet printing for MN coatings, SLA and FDM. While the choice of materials available for use with 3D printing is currently limited, several 3D printers are being developed to utilize a wider material pool. Most techniques for metal $\mathrm{MN}$ production are costly and require sophisticated equipment limiting their scalability. Fabrication technique choices are higher for polymeric MNs and a comparative cost assessment may be performed to select the most costeffective technique. It is, however, important to note that additional costs of sterilization and improved packaging may be added for certain polymers and drugs.

The number of MN-based research publications is on the rise. While numerous in-vivo studies provide proof-of-concept for delivering new therapeutic agents, more practical studies for $\mathrm{MN}$ development in terms of long-term storage stability, cost of production and fate of polymer in the body are largely limited. MN commercialization is on the way and answering these key questions will ensure creation of a thriving market.

\section{Acknowledgements}

This work was partially funded by the Indian Council of Medical Research (ICMR, ITR 2015-0010).

\section{References}

1. Blanco E, Shen H and Ferrari M 2015 Principles of nanoparticle design for overcoming biological barriers to drug delivery Nat. Biotechnol. 33941

2. Bhatnagar S, Dave K and Venuganti V V K 2017 Microneedles in the clinic J. Control Release 260164

3. Kim Y C, Park J H and Prausnitz M R 2012 Microneedles for drug and vaccine delivery Adv. Drug Deliv. Rev. 641547

4. Traverso G, Schoellhammer C M, Schroeder A, Maa R, Lauwers G Y, Polat B E, Anderson D G, Blankschtein D and Langer R 2015 Microneedles for drug delivery via the gastrointestinal tract J. Pharm. Sci. 104362

5. Jiang J, Gill H S, Ghate D, McCarey B E, Patel S R, Edelhauser H F and Prausnitz M R 2007 Coated microneedles for drug delivery to the eye Invest. Ophthalmol. Vis. Sci. 484038

6. Larrañeta E, Lutton R E M, Woolfson A D and Donnelly R F 2016 Microneedle arrays as transdermal and intradermal drug delivery systems: materials science, manufacture and commercial development Mater. Sci. Eng. R Rep. 1041

7. Pamornpathomkul B, Ngawhirunpat T, Tekko I A, Vora L, McCarthy H O and Donnelly R F 2018 Dissolving polymeric microneedle arrays for enhanced site-specific acyclovir delivery Eur. J. Pharm. Sci. 121 200

8. Mukerjee E V, Collins S D, Isseroff R R and Smith R L 2004 Microneedle array for transdermal biological fluid extraction and in situ analysis Sens. Actuat. A Phys. 114267

9. Donnelly R F, Mooney K, McCrudden M T, VicentePerez E M, Belaid L, Gonzalez-Vazquez P, McElnay J C and Woolfson A D 2014 Hydrogel-forming microneedles increase in volume during swelling in skin, but skin barrier function recovery is unaffected J. Pharm. Sci. 1031478

10. Henstock J R, Canham L T and Anderson S I 2015 Silicon: the evolution of its use in biomaterials Acta Biomater. 1117

11. Donnelly R F, Morrow D I J, Fay F, Scott C J, Abdelghany S, Singh R R T, Garland M J and David Woolfson A 2010 Microneedle-mediated intradermal nanoparticle delivery: potential for enhanced local administration of hydrophobic pre-formed photosensitisers Photodiagn. Photodyn. Ther. 7222

12. Hench L L and Wilson J 1986 Biocompatibility of silicates for medical use Ciba Found Symp. 121231

13. Iacocca R G, Toltl N, Allgeier M, Bustard B, Dong X, Foubert M, Hofer J, Peoples S and Shelbourn T 2010 Factors affecting the chemical durability of glass used in the pharmaceutical industry AAPS PharmSciTech 111340

14. Chambers R and Chambers E L 1961 Explorations into the nature of the living cell Acad. Med. 36966

15. Poggesi C, Tesi C and Stehle R 2005 Sarcomeric determinants of striated muscle relaxation kinetics Pflügers Archiv 449505

16. Tombe P P D, Belus A, Piroddi N, Scellini B, Walker J S, Martin A F, Tesi C and Poggesi C 2007 
Myofilament calcium sensitivity does not affect crossbridge activation-relaxation kinetics Am. J. Physiol. Regul. Integr. Comp. Physiol. 292 R1129

17. Gupta J, Felner E I and Prausnitz M R 2011 Rapid pharmacokinetics of intradermal insulin administered using microneedles in type 1 diabetes subjects Diabetes Technol. Ther. 13451

18. Wang P M, Cornwell M and Prausnitz M R 2005 Minimally invasive extraction of dermal interstitial fluid for glucose monitoring using microneedles Diabetes Technol. Ther.7 131

19. Wang P M, Cornwell M, Hill J and Prausnitz M R 2006 Precise microinjection into skin using hollow microneedles J. Invest. Dermatol. 1261080

20. Ayittey P N, Walker J S, Rice J J and De Tombe P P 2009 Glass microneedles for force measurements: a finite-element analysis model Pflugers Arch. 4571415

21. http://www.grantadesign.com. Accessed 16 March 2019

22. Bouras N, Madjoubi M, Kolli M, Benterki S and Hamidouche M 2009 Thermal and mechanical characterization of borosilicate glass Phys. Procedia 21135

23. Ashby M F 2012 Materials and the Environment: Ecoinformed Material Choice (Oxford: Elsevier)

24. Hopcroft M A, Nix W D and Kenny T W 2010 What is the Young's modulus of silicon? J. Microelectromech. Syst. 19229

25. Petersen K E 1982 Silicon as a mechanical material $P$. IEEE 70420

26. Giallonardo J D, Erb U, Aust K T and Palumbo G 2011 The influence of grain size and texture on the Young's modulus of nanocrystalline nickel and nickeliron alloys Philos. Mag. 914594

27. Meshram S D, Mohandas T and Reddy G M 2007 Friction welding of dissimilar pure metals J. Mater. Process. Technol. 184330

28. Zhou Y L, Niinomi M and Akahori T 2004 Dynamic Young's modulus and mechanical properties of Ti-Hf alloys Mater. Trans. 451549

29. Information from http://asm.matweb.com. Accessed on 16 March 2019

30. Seidemann V, Bütefisch S and Büttgenbach S 2002 Fabrication and investigation of in-plane compliant SU8 structures for MEMS and their application to micro valves and micro grippers Sens. Actuat. A Phys. 97457

31. Svensson R B, Hassenkam T, Grant C A and Magnusson S P 2010 Tensile properties of human collagen fibrils and fascicles are insensitive to environmental salts Biophys. J. 994020

32. Buehler M J 2006 Nature designs tough collagen: explaining the nanostructure of collagen fibrils Proc. Natl. Acad. Sci. USA 10312285

33. Oun A A and Rhim J-W 2015 Preparation and characterization of sodium carboxymethyl cellulose/cotton linter cellulose nanofibril composite films Carbohydr. Polym. 127101

34. Engelberg I and Kohn J 1991 Physico-mechanical properties of degradable polymers used in medical applications: a comparative study Biomaterials 12292

35. Gentile P, Chiono V, Carmagnola I and Hatton P V 2014 An overview of poly(lactic-co-glycolic) acid
(PLGA)-based biomaterials for bone tissue engineering Int. J. Mol. Sci. 153640

36. Gong S, Wang H, Sun Q, Xue S-T and Wang J-Y 2006 Mechanical properties and in vitro biocompatibility of porous zein scaffolds Biomaterials 273793

37. Mandapalli P K, Labala S, Chawla S, Janupally R, Sriram D and Venuganti V V K 2017 Polymer-gold nanoparticle composite films for topical application: evaluation of physical properties and antibacterial activity Polym. Compos. 382829

38. K Chan, H Senin and I Naimah 2009 (Eds.) Structural And Mechanical Properties Of Polyvinyl Alcohol (Pva) Thin Film. AIP Conference Proceedings; 2009: AIP

39. Bauccio M 1994 ASM Engineered Materials Reference Book (Ohio: ASM International)

40. Orlovskii V, Komlev V and Barinov S 2002 Hydroxyapatite and hydroxyapatite-based ceramics Inorg. Mater. 38973

41. Evis Z and Ozturk F 2008 Investigation of tensile strength of hydroxyapatite with various porosities by diametral strength test Mater. Sci. Tech. 24474

42. Jeon O, Song S J, Lee K-J, Park M H, Lee S-H, Hahn S K, Kim S and Kim B-S 2007 Mechanical properties and degradation behaviors of hyaluronic acid hydrogels cross-linked at various cross-linking densities Carbohydr. Polym. 70251

43. Liu M, Sun J, Sun Y, Bock C and Chen Q 2009 Thickness-dependent mechanical properties of polydimethylsiloxane membranes J. Micromech. Microeng. 19035028

44. Czerner M, Fellay L S, Suárez M P, Frontini P M and Fasce L A 2015 Determination of elastic modulus of gelatin gels by indentation experiments Procedia Mater. Sci. 8287

45. Rhim J-W 2004 Physical and mechanical properties of water resistant sodium alginate films LWT Food Sci. Technol. 37323

46. Hermawan H, Ramdan D and Djuansjah J R 2011 Metals for biomedical applications. Biomedical engineering-from theory to applications: InTech; 2011

47. Loizidou E Z, Williams N A, Barrow D A, Eaton M J, McCrory J, Evans S L and Allender C J 2015 Structural characterisation and transdermal delivery studies on sugar microneedles: Experimental and finite element modelling analyses Eur. J. Pharm. Biopharm. 89224

48. Devi S and Williams D 2013 Morphological and compressional mechanical properties of freeze-dried mannitol, sucrose, and trehalose cakes J. Pharm. Sci. 1024246

49. Yoshinari T, Forbes R T, York P and Kawashima Y 2003 The improved compaction properties of mannitol after a moisture-induced polymorphic transition Int. J. Pharm. 258121

50. Raphael A P, Crichton M L, Falconer R J, Meliga S, Chen X, Fernando G J P, Huang H and Kendall M A F 2016 Formulations for microprojection/microneedle vaccine delivery: structure, strength and release profiles J. Control Release 22540

51. Demir Y K, Akan Z and Kerimoglu O 2013 Characterization of polymeric microneedle arrays for transdermal drug delivery PLoS ONE 8 e 77289 
52. https://www.engineeringtoolbox.com/polymer-proper ties-d_1222.html. Accessed on 14 March 2019

53. http://www-mdp.eng.cam.ac.uk/web/library/enginfo/ cueddatabooks/materials.pdf. Accessed on 14 March 2019

54. Radhakrishnan J, Padaki V and Singh U 2017 Mechanical failure analysis of needles, for microneedle array dry-electrodes Def. Life Sci. J. 2448

55. Information from http://www.mit.edu/ 6.777/mat props/alox.htm. Accessed on 14 March 2019

56. Information from https://www.engineeringtoolbox. com/polymer-properties-d_1222.html. Accessed on 14 March 2019

57. Information from http://www.designerdata.nl/plastics/ thermo+plastics/PMMA. Accessed on 14 March 2019

58. Manivasagam G, Dhinasekaran D and Rajamanickam A 2010 Biomedical implants: corrosion and its prevention-a review Recent Pat. Corros. Sci. 240

59. Brandes E A and Brook G (Eds.) 2013 Smithells Metals Reference Book (Oxford: Butterworth-Heinemann)

60. Niinomi M 1998 Mechanical properties of biomedical titanium alloys Mater. Sci. Eng. A 243231

61. Balagna C, Spriano S and Faga M G 2012 Characterization of Co-Cr-Mo alloys after a thermal treatment for high wear resistance Mater. Sci. Eng. C 321868

62. van der Maaden K, Jiskoot W and Bouwstra J 2012 Microneedle technologies for (trans)dermal drug and vaccine delivery J. Control Release 161645

63. Dharadhar S, Majumdar A, Dhoble S and Patravale V 2019 Microneedles for transdermal drug delivery: a systematic review Drug Dev. Ind. Pharm. 45188

64. Vinayakumar K B, Hegde G M, Nayak M M, Dinesh N S and Rajanna K 2014 Fabrication and characterization of gold coated hollow silicon microneedle array for drug delivery Microelectron. Eng. 12812

65. Mikszta J A, Alarcon J B, Brittingham J M, Sutter D E, Pettis R J and Harvey N G 2002 Improved genetic immunization via micromechanical disruption of skinbarrier function and targeted epidermal delivery Nat. Med. 8415

66. McAllister D V, Wang P M, Davis S P, Park J-H, Canatella P J, Allen M G and Prausnitz M R 2003 Microfabricated needles for transdermal delivery of macromolecules and nanoparticles: fabrication methods and transport studies Proc. Natl. Acad. Sci USA 10013755

67. Gill H S and Prausnitz M R 2007 Coated microneedles for transdermal delivery J. Control Release 117227

68. Daddona P E, Matriano J A, Mandema J and Maa Y-F 2011 Parathyroid hormone (1-34)-coated microneedle patch system: clinical pharmacokinetics and pharmacodynamics for treatment of osteoporosis Pharm. Res. 28159

69. Boks M A, Unger W W, Engels S, Ambrosini M, van Kooyk Y and Luttge R 2015 Controlled release of a model vaccine by nanoporous ceramic microneedle arrays Int. J. Pharm. 491375

70. Cai B, Xia W, Bredenberg S, Li H and Engqvist H 2015 Bioceramic microneedles with flexible and selfswelling substrate Eur. J. Pharm. Biopharm. 94404

71. Barsoum M and Barsoum M 2002 Fundamentals of Ceramics (New York: Taylor and Francis)
72. Krajewski A, Ravaglioli A, Roncari E, Pinasco P and Montanari L 2000 Porous ceramic bodies for drug delivery J. Mater. Sci. Mater. Med. 11763

73. Olhero S, Lopes E and Ferreira J 2016 Fabrication of ceramic microneedles-the role of specific interactions between processing additives and the surface of oxide particles in Epoxy Gel Casting J. Eur. Ceram. Soc. 364131

74. Saini M, Singh Y, Arora P, Arora V and Jain K 2015 Implant biomaterials: a comprehensive review World J. Clin. Cases 352

75. Yu W, Jiang G, Liu D, Li L, Chen H, Liu Y, Huang Q, Tong Z, Yao J and Kong X 2017 Fabrication of biodegradable composite microneedles based on calcium sulfate and gelatin for transdermal delivery of insulin Mater. Sci. Eng. C 71725

76. Yu W, Jiang G, Liu D, Li L, Tong Z, Yao J and Kong X 2017 Transdermal delivery of insulin with bioceramic composite microneedles fabricated by gelatin and hydroxyapatite Mater. Sci. Eng. C 73425

77. Metroke T L, Parkhill R L and Knobbe E T 2001 Passivation of metal alloys using sol-gel-derived materials-a review Prog. Org. Coat. 41233

78. Cai B, Xia W, Bredenberg S and Engqvist H 2014 Self-setting bioceramic microscopic protrusions for transdermal drug delivery J. Mater. Chem. B 25992

79. Kolli C S and Banga A K 2008 Characterization of solid maltose microneedles and their use for transdermal delivery Pharm. Res. 25104

80. Li G, Badkar A, Nema S, Kolli C S and Banga A K 2009 In vitro transdermal delivery of therapeutic antibodies using maltose microneedles Int. J. Pharm. 368109

81. Kim H K, Lee S H, Lee B Y, Kim S J, Sung C Y, Jang N K, Kim J D, Jeong D H, Ryu H Y and Lee S 2018 A comparative study of dissolving hyaluronic acid microneedles with trehalose and poly(vinyl pyrrolidone) for efficient peptide drug delivery Biomater. Sci. 62566

82. Zhang Y, Jiang G, Yu W, Liu D and Xu B 2018 Microneedles fabricated from alginate and maltose for transdermal delivery of insulin on diabetic rats Mater. Sci. Eng. C 8518

83. McGrath M G, Vucen S, Vrdoljak A, Kelly A, O'Mahony C, Crean A M and Moore A 2014 Production of dissolvable microneedles using an atomised spray process: effect of microneedle composition on skin penetration Eur. J. Pharm. Biopharm. 86200

84. Martin C J, Allender C J, Brain K R, Morrissey A and Birchall J C 2012 Low temperature fabrication of biodegradable sugar glass microneedles for transdermal drug delivery applications J. Control Release 158 93

85. Bhatnagar S, Chawla S R, Kulkarni O P and Venuganti V V K 2017 Zein microneedles for transcutaneous vaccine delivery: fabrication, characterization, and in vivo evaluation using ovalbumin as the model antigen ACS Omega 21321

86. Ito Y, Inagaki Y, Kobuchi S, Takada K and Sakaeda T 2016 Therapeutic drug monitoring of vancomycin in dermal interstitial fluid using dissolving microneedles Int. J. Med. Sci. 13271 
87. Zhu Z, Luo H, Lu W, Luan H, Wu Y, Luo J, Wang Y, Pi J, Lim C Y and Wang H 2014 Rapidly dissolvable microneedle patches for transdermal delivery of exenatide Pharm. Res. 313348

88. Chen B Z, Ashfaq M, Zhang X P, Zhang J N and Guo X D 2018 In vitro and in vivo assessment of polymer microneedles for controlled transdermal drug delivery J. Drug Targ. 26720

89. Mishra R, Bhattacharyya T K and Maiti T K 2015 (Eds.) Theoretical analysis and simulation of SU-8 microneedles for effective skin penetration and drug delivery. 2015 IEEE Sensprs; 2015: IEEE

90. Mishra R, Maiti T K and Bhattacharyya T K 2018 Development of SU-8 hollow microneedles on a silicon substrate with microfluidic interconnects for transdermal drug delivery J. Micromech. Microeng. 28 105017

91. Sun W, Araci Z, Inayathullah M, Manickam S, Zhang X, Bruce M A, Marinkovich M P, Lane A T, Milla C and Rajadas J 2013 Polyvinylpyrrolidone microneedles enable delivery of intact proteins for diagnostic and therapeutic applications Acta Biomater. 97767

92. Lee I-C, Wu Y-C, Tsai S-W, Chen C-H and Wu M-H 2017 Fabrication of two-layer dissolving polyvinylpyrrolidone microneedles with different molecular weights for in vivo insulin transdermal delivery $R S C A d v .75067$

93. Luzuriaga M A, Berry D R, Reagan J C, Smaldone R A and Gassensmith J J 2018 Biodegradable 3D printed polymer microneedles for transdermal drug delivery Lab Chip. 181223

94. Boehm R D, Daniels J, Stafslien S, Nasir A, Lefebvre J and Narayan R J 2015 Polyglycolic acid microneedles modified with inkjet-deposited antifungal coatings Biointerphases 10011004

95. Park J-H, Allen M G and Prausnitz M R 2005 Biodegradable polymer microneedles: fabrication, mechanics and transdermal drug delivery J. Control Release 10451

96. Andersen T E, Andersen A J, Petersen R S, Nielsen L $\mathrm{H}$ and Keller S S 2018 Drug loaded biodegradable polymer microneedles fabricated by hot embossing Microelectron. Eng. 19557

97. Choi S-O, Kim Y C, Park J-H, Hutcheson J, Gill H S, Yoon Y-K, Prausnitz M R and Allen M G 2010 An electrically active microneedle array for electroporation Biomed. Microdev. 12263

98. Oh J-H, Park H-H, Do K-Y, Han M, Hyun D-H, Kim C-G, Kim C-H, Lee S S, Hwang S-J and Shin S-C 2008 Influence of the delivery systems using a microneedle array on the permeation of a hydrophilic molecule, calcein Eur. J. Pharm. Biopharm. 691040

99. Sharma S, Saeed A, Johnson C, Gadegaard N and Cass A E 2017 Rapid, low cost prototyping of transdermal devices for personal healthcare monitoring Sens. Bio Sens. Res. 13104

100. Martin A, McConville A, Anderson A, McLister A and Davis J 2017 Microneedle manufacture: assessing hazards and control measures Safety 325

101. Luangveera W, Jiruedee S, Mama W, Chiaranairungroj M, Pimpin A, Palaga T and Srituravanich W 2015 Fabrication and characterization of novel microneedles made of a polystyrene solution J. Mech. Behav. Biomed. Mater. 5077

102. McCrudden M T, Alkilani A Z, McCrudden C M, McAlister E, McCarthy $\mathrm{H} \mathrm{O}$, Woolfson A D and Donnelly R F 2014 Design and physicochemical characterisation of novel dissolving polymeric microneedle arrays for transdermal delivery of high dose, low molecular weight drugs J. Control Release 18071

103. Hanna K, Yasar-Inceoglu O and Yasar O 2018 Drug delivered poly(ethylene glycol) diacrylate (PEGDA) hydrogels and their mechanical characterization tests for tissue engineering applications MRS Adv. 31697

104. Dardano P, Caliò A, Di Palma V, Bevilacqua M F, Di Matteo A and De Stefano L 2015 A photolithographic approach to polymeric microneedles array fabrication Materials 85484

105. Johnson A R, Caudill C L, Tumbleston J R, Bloomquist C J, Moga K A, Ermoshkin A, Shirvanyants D, Mecham S J, Luft J C and DeSimone J M 2016 Single-step fabrication of computationally designed microneedles by continuous liquid interface production PLOS ONE 11 e0162518

106. Tian Z, Cheng J, Liu J and Zhu Y 2019 Dissolving graphene/poly (acrylic acid) microneedles for potential transdermal drug delivery and photothermal therapy $J$. Nanosci. Nanotechnol. 192453

107. Chen M-C, Ling M-H and Kusuma S J 2015 Poly- $\gamma-$ glutamic acid microneedles with a supporting structure design as a potential tool for transdermal delivery of insulin Acta Biomater. 24106

108. Jin J, Reese V, Coler R, Carter D and Rolandi M 2014 Chitin microneedles for an easy-to-use tuberculosis skin test Adv. Healthc. Mater. 3349

109. Demir Y K, Akan Z and Kerimoglu O 2013 Sodium alginate microneedle arrays mediate the transdermal delivery of bovine serum albumin PLoS ONE 8 e63819

110. Jangid K, Bhargava V and Jayakumar N 2014 A Review: conducting polymers and their applications. Res. J. Pharm. Biol. Chem. Sci. 5383

111. Mülhaupt R 2004 Hermann Staudinger and the origin of macromolecular chemistry Angew. Chem. Int. Ed. 431054

112. Huang $\mathrm{H}$ and Fu C 2007 Different fabrication methods of out-of-plane polymer hollow needle arrays and their variations J. Micromech. Microeng. 17393

113. Eltayib E, Brady A J, Caffarel-Salvador E, GonzalezVazquez P, Alkilani A Z, McCarthy H O, McElnay J C and Donnelly R F 2016 Hydrogel-forming microneedle arrays: potential for use in minimally-invasive lithium monitoring Eur. J. Pharm. Biopharm. 102123

114. Bhatnagar S, Bankar N G, Kulkarni M V and Venuganti V V K 2019 Dissolvable microneedle patch containing doxorubicin and docetaxel is effective in 4T1 xenografted breast cancer mouse model Int. J. Pharm. 556263

115. Bhatnagar S, Saju A, Cheerla K D, Gade S K, Garg P and Venuganti V V K 2018 Corneal delivery of besifloxacin using rapidly dissolving polymeric microneedles Drug Deliv. Transl. Res. 8473

116. Bhatnagar S, Kumari P, Pattarabhiran S P and Venuganti V V K 2018 Zein Microneedles for 
Localized Delivery of Chemotherapeutic Agents to Treat Breast Cancer: Drug Loading, Release Behavior, and Skin Permeation Studies AAPS PharmSciTech 19 1818

117. Park J-H, Choi S-O, Kamath R, Yoon Y-K, Allen M G and Prausnitz M R 2007 Polymer particle-based micromolding to fabricate novel microstructures Biomed. Microdev. 9223

118. Donnelly R F, Majithiya R, Singh T R R, Morrow D I J, Garland M J, Demir Y K, Migalska K, Ryan E, Gillen D, Scott C J and Woolfson A D 2011 Design, optimization and characterisation of polymeric microneedle arrays prepared by a novel laser-based micromoulding technique Pharm. Res. 2841

119. Park J-H, Allen M G and Prausnitz M R 2006 Polymer microneedles for controlled-release drug delivery Pharm. Res. 231008

120. Xiang Z, Wang H, Pant A, Pastorin G and Lee C 2013 Development of vertical SU-8 microtubes integrated with dissolvable tips for transdermal drug delivery Biomicrofluidics 7026502

121. Chu L Y and Prausnitz M R 2011 Separable arrowhead microneedles J. Control Release 149242

122. Fukushima K, Ise A, Morita H, Hasegawa R, Ito Y, Sugioka N and Takada K 2011 Two-layered dissolving microneedles for percutaneous delivery of peptide/ protein drugs in rats Pharm. Res. 287

123. Chen M C, Ling M H, Wang K W, Lin Z W, Lai B H and Chen D H 2015 Near-infrared light-responsive composite microneedles for on-demand transdermal drug delivery Biomacromolecules 161598

124. Caffarel-Salvador E, Brady A J, Eltayib E, Meng T, Alonso-Vicente A, Gonzalez-Vazquez P, Torrisi B M, Vicente-Perez E M, Mooney K, Jones D S, Bell S E J, McCoy C P, McCarthy H O, McElnay J C and Donnelly R F 2016 Hydrogel-forming microneedle arrays allow detection of drugs and glucose in vivo: potential for use in diagnosis and therapeutic drug monitoring PLOS ONE 10 e0145644

125. Pettus J and Edelman S V 2017 Recommendations for using real-time continuous glucose monitoring (rtCGM) data for insulin adjustments in type 1 diabetes J. Diabetes Sci. Technol. 11138

126. Hu X, Yu J, Qian C, Lu Y, Kahkoska A R, Xie Z, Jing $\mathrm{X}$, Buse J B and $\mathrm{Gu} \mathrm{Z} 2017 \mathrm{H}_{2} \mathrm{O}_{2}$-responsive vesicles integrated with transcutaneous patches for glucosemediated insulin delivery ACS Nano 11613

127. Yu J, Qian C, Zhang Y, Cui Z, Zhu Y, Shen Q, Ligler F S, Buse J B and Gu Z 2017 Hypoxia and $\mathrm{H}_{2} \mathrm{O}_{2}$ dualsensitive vesicles for enhanced glucose-responsive insulin delivery Nano Lett. 17733

128. Wang J, Ye Y, Yu J, Kahkoska A R, Zhang X, Wang C, Sun W, Corder R D, Chen Z and Khan S A 2018 Core-shell microneedle gel for self-regulated insulin delivery ACS Nano 122466

129. Kim H-G, Gater D L and Kim Y-C 2018 Development of transdermal vitamin D3 (VD3) delivery system using combinations of PLGA nanoparticles and microneedles Drug Deliv. Transl. Res. 8281

130. Zaric M, Lyubomska O, Touzelet O, Poux C, AlZahrani S, Fay F, Wallace L, Terhorst D, Malissen B and Henri S 2013 Skin dendritic cell targeting via microneedle arrays laden with antigen-encapsulated poly-D, L-lactide-co-glycolide nanoparticles induces efficient antitumor and antiviral immune responses ACS Nano 72042

131. Niu L, Chu L Y, Burton S A, Hansen K J and Panyam J 2019 Intradermal delivery of vaccine nanoparticles using hollow microneedle array generates enhanced and balanced immune response J. Control Release 294 268

132. Lan X, She J, Lin D-a, Xu Y, Li X, Yang W-f, Lui V W Y, Jin L, Xie X and Su Y-X 2018 Microneedlemediated delivery of lipid-coated cisplatin nanoparticles for efficient and safe cancer therapy ACS Appl. Mater. Interfaces 1033060

133. van der Maaden K, Varypataki E M, Romeijn S, Ossendorp F, Jiskoot W and Bouwstra J 2014 Ovalbumin-coated $\mathrm{pH}$-sensitive microneedle arrays effectively induce ovalbumin-specific antibody and T-cell responses in mice Eur. J. Pharm. Biopharm. 88310

134. Duong H T T, Kim N W, Thambi T, Giang Phan V H, Lee M S, Yin Y, Jeong J H and Lee D S 2018 Microneedle arrays coated with charge reversal $\mathrm{pH}$ sensitive copolymers improve antigen presenting cellshoming DNA vaccine delivery and immune responses J.Control Release 269225

135. Martanto W, Moore J S, Kashlan O, Kamath R, Wang P M, O'Neal J M and Prausnitz M R 2006 Microinfusion using hollow microneedles Pharm. Res. 23104

136. Ayittey P N, Walker J S, Rice J J and de Tombe P P 2008 Glass microneedles for force measurements: a finite-element analysis model Pflüg. Arch. Eur. J. Phy. 4571415

137. Park S Y, Lee H U, Lee Y-C, Kim G H, Park E C, Han S H, Lee J G, Choi S, Heo N S, Kim D L, Huh Y S and Lee J 2014 Wound healing potential of antibacterial microneedles loaded with green tea extracts Mater. Sci. Eng. C 42757

138. Larrañeta E, Lutton R E M, Brady A J, Vicente-Pérez E M, Woolfson A D, Thakur R R S and Donnelly R F 2015 Microwave-assisted preparation of hydrogelforming microneedle arrays for transdermal drug delivery applications Macromol. Mater. Eng. 300586

139. Ali A A, McCrudden C M, McCaffrey J, McBride J W, Cole G, Dunne N J, Robson T, Kissenpfennig A, Donnelly R F and McCarthy H O 2017 DNA vaccination for cervical cancer; a novel technology platform of RALA mediated gene delivery via polymeric microneedles Nanomedicine 13921

140. Korkmaz E, Friedrich E E, Ramadan M H, Erdos G, Mathers A R, Burak Ozdoganlar O, Washburn N R and Falo L D 2015 Therapeutic intradermal delivery of tumor necrosis factor-alpha antibodies using tip-loaded dissolvable microneedle arrays Acta Biomater. 2496

141. Ling M-H and Chen M-C 2013 Dissolving polymer microneedle patches for rapid and efficient transdermal delivery of insulin to diabetic rats Acta Biomater. 98952

142. Watanabe T, Hagino K and Sato T 2014 Evaluation of the effect of polymeric microneedle arrays of varying geometries in combination with a high-velocity applicator on skin permeability and irritation Biomed. Microdev. 16591 
143. Lippmann J M, Geiger E J and Pisano A P 2007 Polymer investment molding: Method for fabricating hollow, microscale parts Sens. Actuators A Phys. 1342

144. Moon S J, Lee S S, Lee H S and Kwon T H 2005 Fabrication of microneedle array using LIGA and hot embossing process Microsyst. Technol. 11311

145. Li J, Zhou Y, Yang J, Ye R, Gao J, Ren L, Liu B, Liang L and Jiang L 2019 Fabrication of gradient porous microneedle array by modified hot embossing for transdermal drug delivery Mater. Sci. Eng. C 96 576

146. Norman J J, Choi S-O, Tong N T, Aiyar A R, Patel S R, Prausnitz M R and Allen M G 2013 Hollow microneedles for intradermal injection fabricated by sacrificial micromolding and selective electrodeposition Biomed. Microdev. 15203

147. Park S C, Kim M J, Baek S-K, Park J-H and Choi S-O 2019 Spray-formed layered polymer microneedles for controlled biphasic drug delivery Polymers 11369

148. Sullivan S P, Koutsonanos D G, Del Pilar Martin M, Lee J W, Zarnitsyn V, Choi S O, Murthy N, Compans R W, Skountzou I and Prausnitz M R 2010 Dissolving polymer microneedle patches for influenza vaccination Nat. Med. 16915

149. Gittard S D, Ovsianikov A, Akar H, Chichkov B, Monteiro-Riviere N A, Stafslien S, Chisholm B, Shin C-C, Shih C-M, Lin S-J, Su Y-Y and Narayan R J 2010 Two photon polymerization-micromolding of polyethylene glycol-gentamicin sulfate microneedles Adv. Eng. Mater. 12 B77

150. Luo Z, Sun W, Fang J, Lee K, Li S, Gu Z, Dokmeci M $\mathrm{R}$ and Khademhosseini A 2019 Biodegradable gelatin methacryloyl microneedles for transdermal drug delivery Adv. Healthc. Mater. 81801054

151. Sullivan S P, Murthy N and Prausnitz M R 2008 Minimally invasive protein delivery with rapidly dissolving polymer microneedles Adv. Mater. 20933

152. Boehm R D, Miller P R, Schell W A, Perfect J R and Narayan R J 2013 Inkjet printing of amphotericin B onto biodegradable microneedles using piezoelectric inkjet printing JOM 65525

153. Pere C P P, Economidou S N, Lall G, Ziraud C, Boateng J S, Alexander B D, Lamprou D A and Douroumis D 2018 3D printed microneedles for insulin skin delivery Int. J. Pharm. 544425

154. Lee K and Jung H 2012 Drawing lithography for microneedles: a review of fundamentals and biomedical applications Biomaterials 337309

155. Lee K, Lee C Y and Jung H 2011 Dissolving microneedles for transdermal drug administration prepared by stepwise controlled drawing of maltose Biomaterials 323134

156. Kochhar J S, Anbalagan P, Shelar S B, Neo J K, Iliescu C and Kang L 2014 Direct microneedle array fabrication off a photomask to deliver collagen through skin Pharm. Res. 311724

157. Lee J W, Choi S-O, Felner E I and Prausnitz M R 2011 Dissolving microneedle patch for transdermal delivery of human growth hormone Small 7531

158. Doraiswamy A, Jin C, Narayan R J, Mageswaran P, Mente P, Modi R, Auyeung R, Chrisey D B, Ovsianikov A and Chichkov B 2006 Two photon induced polymerization of organic-inorganic hybrid biomaterials for microstructured medical devices Acta Biomater. 2267

159. Gittard S D, Ovsianikov A, Chichkov B N, Doraiswamy A and Narayan R J 2010 Two-photon polymerization of microneedles for transdermal drug delivery Expert Opin. Drug Deliv. 7513

160. Thepsonthi T, Milesi N and Özel T 2012 Design and prototyping of micro-needle arrays for drug delivery using customized tool-based micro-milling process. In Proceedings of the 1st International Conference on Design and Processes for Medical Devices, at Brescia, Italy 2012

161. Zhou W, Ling W-s, Liu W, Peng Y and Peng J 2015 Laser direct micromilling of copper-based bioelectrode with surface microstructure array Opt. Lasers Eng. 737

162. Arai M, Nishinaka Y and Miki N 2015 Electroencephalogram measurement using polymer-based dry microneedle electrode Jpn. J. Appl. Phys. 54 06FP14

163. Martanto W, Davis S P, Holiday N R, Wang J, Gill H S and Prausnitz M R 2004 Transdermal delivery of insulin using microneedles in vivo Pharm. Res. 21947

164. Kim J D, Kim M, Yang H, Lee K and Jung H 2013 Droplet-born air blowing: novel dissolving microneedle fabrication J. Control Release 170430

165. Lee J W, Han M-R and Park J-H 2013 Polymer microneedles for transdermal drug delivery J. Drug Target. 21211

166. Shikida M, Sato K, Tokoro K and Uchikawa D 2000 Differences in anisotropic etching properties of $\mathrm{KOH}$ and TMAH solutions Sens. Actuators A Phys. 80179

167. Lutton R E M, Larrañeta E, Kearney M-C, Boyd P, Woolfson A D and Donnelly R F 2015 A novel scalable manufacturing process for the production of hydrogel-forming microneedle arrays Int. J. Pharm. 494417

168. Trautmann A, Heuck F, Mueller C, Ruther P and Paul O 2005 (Eds.) Replication of microneedle arrays using vacuum casting and hot embossing. In The $13^{\text {th }}$ International Conference on Solid-State Sensors, Actuators and Microsystems, 2005. Digest of Technical Papers. Transducers '05; 2005 5-9 June, Seoul, South Korea

169. Information from http://www.raphas.com/rnd/dab-tech nique/?ckattempt=1. Accessed on 13 March 2019

170. Boehm R D, Miller P R, Daniels J, Stafslien S and Narayan R J 2014 Inkjet printing for pharmaceutical applications Mater. Today 17247

171. Uddin M J, Scoutaris N, Klepetsanis P, Chowdhry B, Prausnitz M R and Douroumis D 2015 Inkjet printing of transdermal microneedles for the delivery of anticancer agents Int. J. Pharm. 494593

172. Ross S, Scoutaris N, Lamprou D, Mallinson D and Douroumis D 2015 Inkjet printing of insulin microneedles for transdermal delivery Drug Deliv. Transl. Res. 5451

173. Allen E A, O’Mahony C, Cronin M, O’Mahony T, Moore A C and Crean A M 2016 Dissolvable microneedle fabrication using piezoelectric dispensing technology Int. J. Pharm. $\mathbf{5 0 0} 1$

174. Gittard S D, Miller P R, Jin C, Martin T N, Boehm R D, Chisholm B J, Stafslien S J, Daniels J W, Cilz N, 
Monteiro-Riviere N A, Nasir A and Narayan R J 2011 Deposition of antimicrobial coatings on microstereolithography-fabricated microneedles JOM 6359

175. Economidou S N, Lamprou D A and Douroumis D 2018 3D printing applications for transdermal drug delivery Int. J. Pharm. 544415

176. Vallet-Regí M, Colilla M, Izquierdo-Barba I and Manzano M 2017 Mesoporous silica nanoparticles for drug delivery: current insights Molecules 2347

177. Pradeep Narayanan S and Raghavan S 2018 Fabrication and characterization of gold-coated solid silicon microneedles with improved biocompatibility Int. J. Adv. Manuf. Technol. https://doi.org/10.1007/ s00170-018-2596-3

178. Manam N, Harun W, Shri D, Ghani S, Kurniawan T, Ismail M H and Ibrahim M 2017 Study of corrosion in biocompatible metals for implants: A review J. Alloys Compd. 701698

179. Hayashi K, Matsuguchi N, Uenoyama K and Sugioka Y 1992 Re-evaluation of the biocompatibility of bioinert ceramics in vivo Biomaterials 13195

180. Chevalier J and Gremillard L 2009 Ceramics for medical applications: a picture for the next 20 years $J$. Eur. Ceram. Soc. 291245

181. Duheyne P, Beight J, Cuckler J, Evans B and Radin S 1990 Effect of calcium phosphate coating characteristics on early post-operative bone tissue ingrowth Biomaterials 11531

182. Ducheyne P and Qiu Q 1999 Bioactive ceramics: the effect of surface reactivity on bone formation and bone cell function Biomaterials 202287

183. Ovsianikov A, Chichkov B, Mente P, MonteiroRiviere N A, Doraiswamy A and Narayan R J 2007 Two photon polymerization of polymer-ceramic hybrid materials for transdermal drug delivery Int. J. Appl. Ceram. Technol. 422

184. Markovsky E, Baabur-Cohen H, Eldar-Boock A, Omer L, Tiram G, Ferber S, Ofek P, Polyak D, Scomparin A and Satchi-Fainaro R 2012 Administration, distribution, metabolism and elimination of polymer therapeutics J. Control Release 161446

185. Sato $T$, Ishii $T$ and Okahata $Y 2001$ In vitro gene delivery mediated by chitosan. Effect of $\mathrm{pH}$, serum, and molecular mass of chitosan on the transfection efficiency Biomaterials 222075

186. D’Ayala G, Malinconico M and Laurienzo P 2008 Marine derived polysaccharides for biomedical applications: chemical modification approaches Molecules 132069

187. Aduba D C and Yang H 2017 Polysaccharide fabrication platforms and biocompatibility assessment as candidate wound dressing materials Bioengineering (Basel) 41

188. Liu S, Jin M-n, Quan Y-s, Kamiyama F, Katsumi H, Sakane T and Yamamoto A 2012 The development and characteristics of novel microneedle arrays fabricated from hyaluronic acid, and their application in the transdermal delivery of insulin J. Control Release 161 933

189. Kogan G, Šoltés L, Stern R, Schiller J and Mendichi R 2008 In: Hyaluronic acid: its function and degradation in in vivo systems Studies in Natural Products
Chemistry Atta-ur-Rahman (Ed.) Vol. 34 (Amsterdam: Elsevier) p. 789

190. Lynn A K, Yannas I V and Bonfield W 2004 Antigenicity and immunogenicity of collagen $J$. Biomed. Mater. Res. B Appl. Biomater. 71B 343

191. El-Rashidy A A, Waly G, Gad A, Roether J A, Hum J, Yang Y, Detsch R, Hashem A A, Sami I and Goldmann W H 2018 Antibacterial activity and biocompatibility of zein scaffolds containing silverdoped bioactive glass Biomed. Mater. 13065006

192. Dong J, Sun Q and Wang J-Y 2004 Basic study of corn protein, zein, as a biomaterial in tissue engineering, surface morphology and biocompatibility Biomaterials 254691

193. Voskerician G, Shive M S, Shawgo R S, Von Recum H, Anderson J M, Cima M J and Langer R 2003 Biocompatibility and biofouling of MEMS drug delivery devices Biomaterials 241959

194. Cho S-H, Lu H M, Cauller L, Romero-Ortega M I, Lee J-B and Hughes G A 2008 Biocompatible SU-8-based microprobes for recording neural spike signals from regenerated peripheral nerve fibers IEEE Sens. J. 81830

195. Rezwan K, Chen Q, Blaker J and Boccaccini A R 2006 Biodegradable and bioactive porous polymer/inorganic composite scaffolds for bone tissue engineering Biomaterials 273413

196. Brown A, Zaky S, Ray Jr H and Sfeir C 2015 Porous magnesium/PLGA composite scaffolds for enhanced bone regeneration following tooth extraction Acta Biomater. 11543

197. Ye Y, Yu J, Wen D, Kahkoska A R and Gu Z 2018 Polymeric microneedles for transdermal protein delivery Adv. Drug Deliv. Rev. 127106

198. Böstman O 1991 Absorbable implants for the fixation of fractures JBJS $\mathbf{7 3} 148$

199. Böstman O and Pihlajamäki H 2000 Clinical biocompatibility of biodegradable orthopaedic implants for internal fixation: a review Biomaterials 212615

200. Xu C, Inai R, Kotaki M and Ramakrishna S 2004 Aligned biodegradable nanofibrous structure: a potential scaffold for blood vessel engineering Biomaterials 25877

201. Chen M-C, Chan H-A, Ling M-H and Su L-C 2017 Implantable polymeric microneedles with phototriggerable properties as a patient-controlled transdermal analgesia system J. Mater. Chem. B 5496

202. Pitt C, Chasalow F, Hibionada Y, Klimas D and Schindler A 1981 Aliphatic polyesters. I. The degradation of poly ( $\varepsilon$-caprolactone) in vivo J. Appl. Polym. Sci. 263779

203. Pitt C and Schindler A 1984 Capronor-a biodegradable delivery system for levonorgestrel

204. Ali U, Karim K J B A and Buang N A 2015 A review of the properties and applications of poly (methyl methacrylate)(PMMA) Polym. Rev. 55678

205. Miyagawa S, Sato T and Iguchi T Subchapter 101CBisphenol A In: Y Takei, H Ando, K Tsutsui 2016 (Eds.) Handbook of Hormones (San Diego: Academic Press) p. 577

206. Salman H H and Azcarate I G 2014 Nanoparticles comprising esters of poly (methyl vinyl ether-comaleic anhydride) and uses thereof. Google Patents 
207. Camacho A I, Da Costa Martins R, Tamayo I, de Souza J, Lasarte J J, Mansilla C, Esparza I, Irache J M and Gamazo C 2011 Poly(methyl vinyl ether-comaleic anhydride) nanoparticles as innate immune system activators Vaccine 297130

208. Caló E, Barros J, Ballamy L and Khutoryanskiy V V 2016 Poly (vinyl alcohol)-Gantrez ${ }^{\circledR}$ AN cryogels for wound care applications $R S C A d v .6105487$

209. Paradossi G, Cavalieri F, Chiessi E, Spagnoli C and Cowman M K 2003 Poly (vinyl alcohol) as versatile biomaterial for potential biomedical applications $J$. Mater. Sci. Mater. Med. 14687

210. Hyon S-H, Cha W-I, Ikada Y, Kita M, Ogura Y and Honda Y 1994 Poly (vinyl alcohol) hydrogels as soft contact lens material J. Biomater. Sci. Polym. Ed. 5 397

211. Noguchi T, Yamamuro T, Oka M, Kumar P, Kotoura Y, Hyonyt S H and Ikadat Y 1991 Poly (vinyl alcohol) hydrogel as an artificial articular cartilage: evaluation of biocompatibility J. Appl. Biomater. 2101

212. Liu X, Xu Y, Wu Z and Chen H $2013 \operatorname{Poly}(N-$ vinylpyrrolidone)-modified surfaces for biomedical applications Macromol. Biosci. 13147

213. Robinson B V, Sullivan F M, Borzelleca J F and Schwartz S L 1990 PVP: A Critical Review of the
Kinetics and Toxicology of Polyvinylpyrrolidone (Povidone) (Michigan: Lewis Publishers)

214. Saxena A, Mozumdar S and Johri A K 2006 Ultra-low sized cross-linked polyvinylpyrrolidone nanoparticles as non-viral vectors for in vivo gene delivery Biomaterials 275596

215. McCrudden M T C, Alkilani A Z, Courtenay A J, McCrudden C M, McCloskey B, Walker C, Alshraiedeh N, Lutton R E M, Gilmore B F, Woolfson A D and Donnelly R F 2015 Considerations in the sterile manufacture of polymeric microneedle arrays Drug Deliv. Transl. Res. 53

216. Kim S, Lee J, Shayan F L, Kim S, Huh I, Ma Y, Yang H, Kang G and Jung H 2018 Physicochemical study of ascorbic acid 2-glucoside loaded hyaluronic acid dissolving microneedles irradiated by electron beam and gamma ray Carbohydr. Polym. 180297

217. Prausnitz M R 2017 Engineering microneedle patches for vaccination and drug delivery to skin Annu. Rev. Chem. Biomol. Eng. 8177

218. García L E G, MacGregor M N, Visalakshan R M, Ninan N, Cavallaro A A, Trinidad A D, Zhao Y, Hayball A J D and Vasilev K 2019 Self-sterilizing antibacterial silver-loaded microneedles Chem. Commun. 55171 